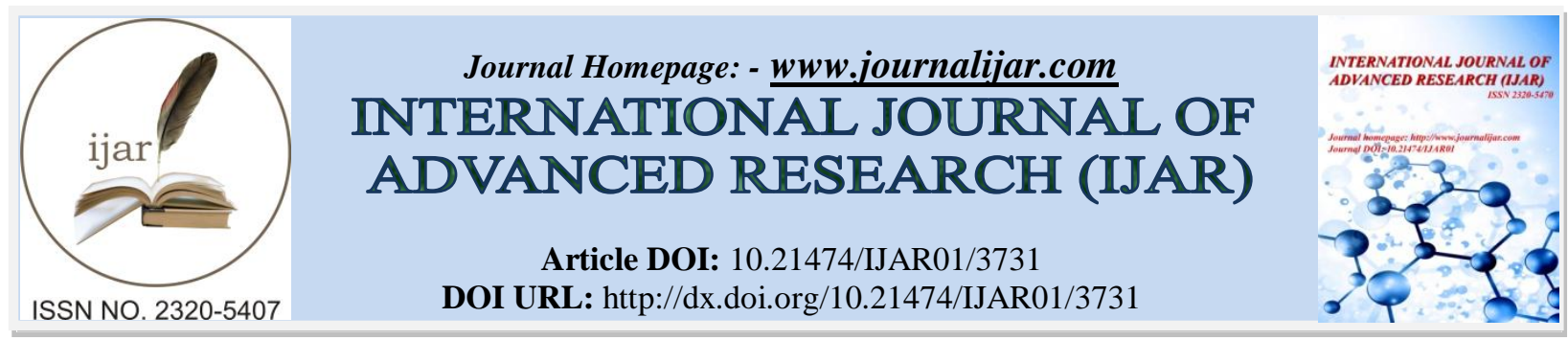

RESEARCH ARTICLE

\title{
EFFECT OF SYNTHESIS CONDITIONS OF CARBON XEROGELS ON THEIR SURFACE CHEMISTRY, PORE TEXTURE AND METHYLENE BLUE ADSORPTION CAPACITY.
}

Maher M. Girgis*, Rabei M. Gabr, Ahmed M. El-Awad and Mahmoud K. Hussien.

Chemistry Department, Faculty of Science, Assiut University, Assiut 71515, Egypt.

\section{Manuscript Info}

Manuscript History

Received: 15 January 2017

Final Accepted: 06 February 2017

Published: March 2017

Key words:-

Carbon xerogels, Surface chemistry,

Pore texture, Methylene blue.

\section{Abstract}

Resorcinol-formaldehyde organic xerogels (OXs) were synthesized by the polycondensation of resorcinol $(\mathrm{R})$ and formaldehyde $(\mathrm{F})$ using two different techniques [microwave (MW) - induced synthesis and conventional (C) synthesis methods]. For the MW-induced synthesis of OXs, five samples variable in their R-F solutions $\mathrm{pH}$ values [in the range 3.0-7.2] were synthesized. These samples were pyrolyzed at 750 ${ }^{\circ} \mathrm{C}$ under $\mathrm{N}_{2}$ flow to give five carbon xerogel (CX) samples. To study the effect of the carbonization temperature, the OX sample prepared at $\mathrm{R}-\mathrm{F}$ solution $\mathrm{pH}$ value of 6.5 was selected and carbonized at different temperatures in the range $600-800^{\circ} \mathrm{C}$, to produce four CX samples. To investigate the effect of the synthesis method on the CX characteristics, another OX sample was prepared by the conventional method at R-F solution $\mathrm{pH}$ value of 6.5 and was carbonized at $750^{\circ} \mathrm{C}$ under $\mathrm{N}_{2}$ flow to give the last CX sample. The effect of the synthesis conditions on the physicochemical and surface chemistry characteristics of the products was performed using different techniques, such as elemental analysis, determination of the surface acidic and basic active sites by the Boehm method, identification of surface functional groups by FTIR, XRD analysis, SEM and TEM investigations. Pore texture characteristics were evaluated by analysis of the respective $\mathrm{N}_{2} / 77 \mathrm{~K}$ adsorptiondesorption isotherms. The methylene blue $(\mathrm{MB})$ number $\left(X_{\mathrm{m}}(\mathrm{mg} / \mathrm{g})\right)$ and surface areas accessible to $\mathrm{MB}\left(\mathrm{S}_{\mathrm{MB}}\right)$ were calculated using the Langmuir and Freundlich adsorption isotherm equations. The Langmuir adsorption isotherm model gives better fit as compared to Freundlich model. Ratios of methylene blue surface area to nitrogen surface area $\left(\mathrm{S}_{\mathrm{MB}} / \mathrm{S}_{\mathrm{N} 2}\right)$ were evaluated and discussed. Removal of $\mathrm{MB}$ from aqueous solution is governed by the chemical nature of the CX surface as well as the diffusion through the intricate internal porosity.

Copy Right, IJAR, 2017,. All rights reserved.

\section{Introduction:-}

Carbon gels are a class of porous carbon materials that have received considerable attention due to their potential applications in fuel cells (Alegre et al.,2012), adsorption (Álvarez and Ribeiro, 2015), bio-sensing (Li et al., 2016), catalysis (Moreno-Castilla and Maldonado-Hódar, 2005), energy storage (Ordeñana-Martínez and Rincón, 2016), and supercapacitors (Lufrano et al., 2011; Zapata-Benabithe et al., 2016). They can be obtained by sol-gel synthesis 
via polymerization reaction between hydroxylated benzenes (such as resorcinol (R)) and formaldehyde (F) (Al-Muhtaseb and Ritter, 2003; Job et al., 2004). After sol-gel polymerization, the solvents used as the reaction media can be removed in three different drying methods; subcritical, supercritical or freezing drying, resulting in xerogels, aerogels and cryogels, respectively (Job et al., 2005). The cheapest and easiest drying method is subcritical drying, which is based on removing the solvent from the gel structure by drying conventionally (at ambient pressure and temperatures of around $100-150{ }^{\circ} \mathrm{C}$ ) to obtain organic gels with high surface areas and pore volumes (Al-Muhtaseb and Ritter, 2003). Pyrolysis of an organic gel under inert atmosphere allows the removal of labile oxygen and hydrogen surface groups, resulting in thermally stable nano structured porous carbon gel. By varying the synthesis conditions, it is possible to obtain carbon gels with different properties (Zubizarreta et al., 2008). Among the parameters that have a great influence on the final gel properties is the $\mathrm{R}-\mathrm{F}$ solutions pH values (Zanto et al., 2002a). During the pyrolysis process, the carbonization temperature (CT) is the most important parameter that has a significant influence on the pore structure of carbon gels (Al-Muhtaseb and Ritter, 2003).

Carbon xerogels (CXs) have very interesting features such as three-dimensional nanosized network (Kakunuri et al., 2015), high porosity and surface area, the possibility of designing their porous texture, outstanding electrical, thermal and mechanical properties and simple manufacturing on a laboratory scale (Calvo et al., 2011). However the main problem of CXs synthesis is the too long time in the conventional preparation method. During the last few years, microwave (MW) radiation has become an accepted heating source for chemical synthesis due to numerous advantages it offers. These include a reduction in synthesis time, an easy and safe method, direct heating of molecules and the avoidance of secondary reactions, giving rise to cleaner products with a higher yield (Gedye, 2002). Therefore, MW radiation has been used to produce carbon gels with a considerable saving of time and energy (Kang et al., 2008).

There are a quite large number of studies regarding the production of OXs, as precursors of CXs, using the conventional synthesis method (Naseri I., et al. 2014). In comparison, there is a great lack in the synthesis of OXs using MW radiation as a heating source and the effect of the synthesis conditions on the OXs produced, and as a result on the CXs characteristics. In addition, a large shortage in the studies regarding the surface chemistry and texture characteristics of MW assisted synthesized CXs was observed, although these features determine their behavior towards various applications. A comparative study between the characteristics of CXs produced under the same condition but with these two different techniques (i.e. MW assisted synthesis and conventional synthesis methods) was not given suitable attention (Calvo et al., 2011).

The object of the present investigation is to examine the influence of the $\mathrm{R}-\mathrm{F}$ solution pH value, as well as the CT on the physicochemical, surface chemistry and pore texture of the MW assisted synthesized CXs, in an attempt to find out the best conditions for preparing high quality CXs by this method. Also, to correlate their surface and textural characteristics with their adsorption capacity for removal of MB (as a standard medium-size organic dyestuff) from aqueous solution. The study was extended, also, to compare the effect of the synthesis method (the MW assisted synthesis and the conventional synthesis methods) on the CX surface chemistry and pore texture characteristics. The results confirmed that there is no need for using the very long conventional synthesis method for CX synthesis, not only because MW assisted method safe a lot of time (5 hours compared with 7 days for the conventional method), but also because it produces higher yield, higher carbon content, more surface functional groups, higher surface area, wider pore volume, and more developed mesoporosity.

\section{Experimental:-}

Synthesis of Organic and Carbon Xerogels:-

Resorcinol-formaldehyde (R-F) organic xerogels (OXs) were synthesized using two different techniques (microwave-induced synthesis and conventional synthesis methods).

\section{Microwave - induced synthesis Method:-}

For the MW-induced synthesis of OXs, the precursor solutions were prepared by the polycondensation of resorcinol and formaldehyde using deionized water as solvent. Resorcinol (Alfa easer, 99\%) was first dissolved in deionized water. Then, formaldehyde (Aldrich, 37 wt. \% in water, stabilized by 10.7 wt. \% methanol) was added under magnetic stirring until obtaining a homogenous solution. The $(\mathrm{R} / \mathrm{F})$ molar ratio was $(0.5)$ and the dilution ratio (i.e. total solvent/ reactant molar ratio) was fixed at (5.70). The dilution ratio includes the added deionized water and the water and methanol contained in the formaldehyde in the case of "total solvent", while "reactant" refers to the resorcinol and formaldehyde. $\mathrm{NaOH}(1 \mathrm{M})$ and $\mathrm{HNO}_{3}(1 \mathrm{M})$ were added to adjust the $\mathrm{pH}$ of the R-F solutions to the 
required $\mathrm{pH}$ values. The precursor solutions were placed in unsealed glass bottles transparent to MW, and these were then introduced into a multimode microwave oven [MILSTONE START SYNTH 1200 W/ 2450 MHZ]. First, the temperature was kept at $85^{\circ} \mathrm{C}$ for $\sim 3 \mathrm{~h}$ for gelation and permitting part of the curing stage to take place. Then, the microwave device was allowed to operate at power (750 Watt) until synthesis had been completed. The total synthesis time of the OX was around 5h. Five OX samples variable in their R-F solutions $\mathrm{pH}$ values (between 3.0 and 7.2) were synthesized. These samples were designated as OX3.0(MW), OX5.0(MW), OX6.0(MW), OX6.5(MW) and OX7.2(MW), where the letters OX refer to the organic xerogel and the numbers indicate the R-F solution $\mathrm{pH}$ value, whereas (MW) indicates the use of MW-induced synthesis method. Pictures of the OX6.5(MW) sample obtained by the MW induced synthesis method are given in Figure 1(a).

(a)
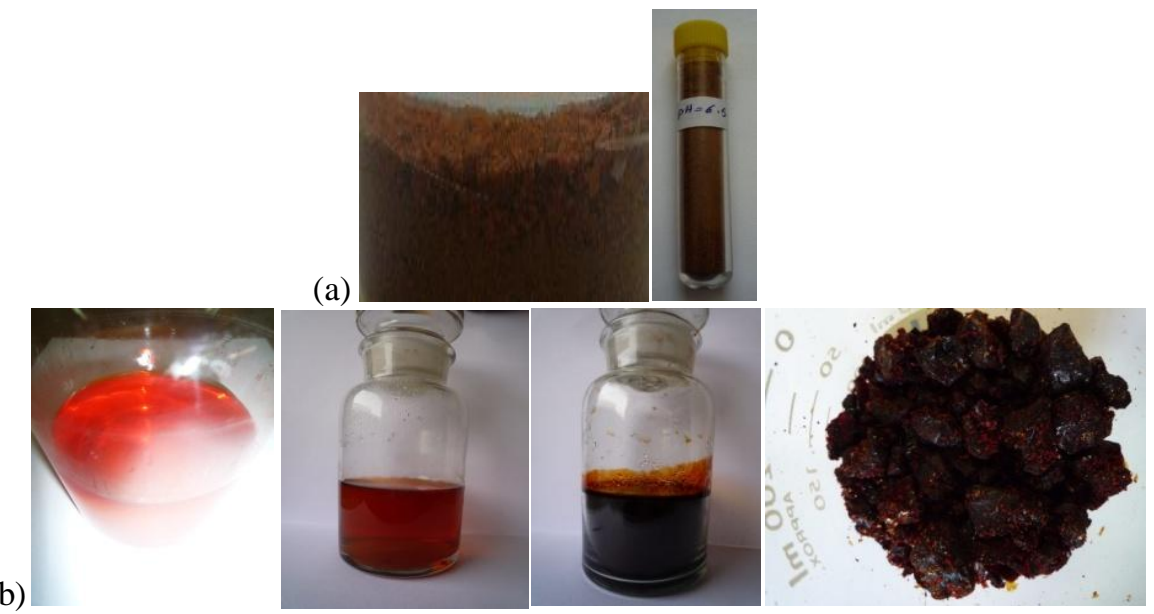

Fig. 1:- Photos of the OX6.5(MW) sample prepared by the MW assisted synthesis method (a), and of the steps of the conventional synthesis method of the OX6.5(C) sample (b).

To study the effect of the R-F solutions $\mathrm{pH}$ values on the carbon xerogels characteristics, the OX samples were pyrolyzed at a fixed temperature $\left(750^{\circ} \mathrm{C}\right)$ under nitrogen flow in a vertical tubular quartz reactor for $2 \mathrm{~h}$. with a heating rate of $50{ }^{\circ} \mathrm{C}$. $\mathrm{min}^{-1}$ to give CXs. These samples were designated as CX3.0(MW)750, CX5.0(MW)750, CX6.0(MW)750, CX6.5(MW)750 and CX7.2(MW)750, where the last number indicates the carbonization temperature. For studying the effect of the carbonization temperature, the OX6.5(MW) sample was selected and pyrolyzed, as described above, at different temperatures in the range $600-800{ }^{\circ} \mathrm{C}$, to produce four CXs variable in their CT. These samples were designated as CX6.5(MW)600, CX6.5(MW)700, CX6.5(MW)750, and CX6.5(MW)800.

\section{Conventional synthesis Method:-}

To study the effect of synthesis method on the CX characteristics, another OX sample was prepared by the conventional method at $\mathrm{R}-\mathrm{F}$ solution $\mathrm{pH}$ value of 6.5 and $\mathrm{CT}$ of $750{ }^{\circ} \mathrm{C}$ to give the last $\mathrm{CX}$ sample. These conditions were found to be the best effective ones on the characteristics of the CXs prepared by the MW-induced synthesis method. To synthesize the OX sample by the conventional method, the $\mathrm{pH}$ was adjusted to the required value (6.5) using $\mathrm{NaOH}$ and $\mathrm{HNO}_{3}$. The solution was placed in a stopper bottle, which was then introduced in an electrical oven at $85{ }^{\mathrm{O}} \mathrm{C}$ for $72 \mathrm{~h}$. to undergo gelation and curing stages. Afterwards, the bottle was opened and the oven temperature was set at $100{ }^{\circ} \mathrm{C}$ for 4 days with the purpose of drying the organic gel via evaporation of the solvent until the process of drying of the organic gel was ended. This sample was designated as OX6.5(C), where (C) indicates the synthesis using the conventional method. Pictures of the steps of the conventional synthesis method of the OX6.5(C) sample are given in Figure 1(b). Finally, the OX6.5(C) sample was pyrolyzed at $750^{\circ} \mathrm{C}$ under nitrogen flow. This sample was designated as CX6.5(C)750.

\section{Physicochemical and Surface Chemistry Studies:-}

Determination of the $\mathrm{pH}$ of the Investigated Carbon Xerogels:-

For measuring the $\mathrm{pH}$ values of aqueous suspensions of the $\mathrm{CX}$ samples, 1.0 gram portions of finely powdered carbon were mixed with $20 \mathrm{~cm}^{3}$ distilled water in $50 \mathrm{~cm}^{3}$ capacity stopper Pyrex bottles. The suspensions were 
shaken mechanically for $48 \mathrm{~h}$. at $25^{\circ} \mathrm{C}$, following which their $\mathrm{pH}$ values were determined using a Jenway $3510 \mathrm{pH}$ meter.

\section{Elemental Analysis:-}

The carbon, hydrogen and oxygen contents of the samples were analyzed using Elementary Analyzing-System GmbH, Vario EL V2.3.07 July 1998, CHNS Mode. For the sake of quality assurance and quality control, duplicated analysis was conducted on all samples.

\section{Determination of Active Sites:-}

The acidic and basic active sites were determined according to the method of Boehm (Boehm, 2002). $0.2 \mathrm{~g}$ of CX sample was placed in $25 \mathrm{ml}$ of the following $(0.1 \mathrm{~N})$ solutions: sodium hydroxide, sodium carbonate, sodium bicarbonate and hydrochloric acid. The vials were sealed and shaken for $24 \mathrm{~h}$. and then $5 \mathrm{ml}$ of each filtrate was pipetted and the excess of base and acid was titrated with standard $\mathrm{HCl}$ and $\mathrm{NaOH}$, respectively. The numbers of acidic sites of various types were calculated under the assumption that $\mathrm{NaOH}$ neutralizes carboxyl, phenolic and lactonic groups, while $\mathrm{Na}_{2} \mathrm{CO}_{3}$ neutralizes carboxyl and lactonic groups, and $\mathrm{NaHCO}_{3}$ neutralizes only carboxyl groups. The number of surface basic sites was calculated from the amount of $\mathrm{HCl}$ which reacted with the CX.

\section{FTIR Analysis:-}

The FTIR spectra of the CX samples were recorded using the $\mathrm{KBr}$ disc technique in the range $4000-400 \mathrm{~cm}^{-1}$ at the resolution of a Genesis-II Fourier transform infrared spectrophotometer, Shimadzu (Japan), model (Nicolet 6700). About $10 \mathrm{mg}$ of the finally powdered sample was mixed well with $200 \mathrm{mg}$ of $\mathrm{KBr}$ powder (spectroscopically pure) in mortar. The mixture was then pressed in a special disc under vacuum at about $8 \mathrm{ton} / \mathrm{cm}^{2}$ by means of a hydraulic press. The disc produced was $1.2 \mathrm{~cm}$ in diameter and about $0.7 \mathrm{~mm}$ thickness.

\section{XRD Analysis:-}

XRD patterns for the CX samples were recorded using a Philips type Diffractometer (Model PW 2103/00) using Nifiltered $\mathrm{Cu} \mathrm{K} \alpha$ radiation at $\lambda=1.5418 \AA$. The powders were mounted on silicon monocrystal sample holders. Data acquisition was realized in the range $\left(4-80^{\circ}\right)$ with scan step size of $0.04^{\circ}$. The average particle size of each sample was calculated from Scherrer formula (Khetre et al., 2011) $(t=K \lambda / \beta \cos \theta$, where $t$ is the average size of the particles, assuming particles are spherical, $\mathrm{K}=0.9, \lambda$ is the wave length of $\mathrm{X}$-ray radiation, $\beta$ is the full width at half maximum of the diffracted peak and $\theta$ is the angle of diffraction).

\section{Scanning Electron Microscope (SEM) Investigations:-}

Scanning electron micrographs of the CX6.5(MW)750 sample were obtained using a JEOL Scanning Microscope, Model JSM-5400 LV (Jeol, Tokyo, Japan). The sample was prepared by the gold sputtering technique (Girgis, 1993), by sprinkling the powder lightly onto a double-sides adhesive tape, which was mounted on a SEM specimen stub. The edge of the double-sided tape was coated with silver paint to minimize charging. Finally, the sample was sputter-coated with gold. Micrographs were obtained in a secondary electron imaging mode using a potential difference of $25 \mathrm{kV}$.

Transmission Electron Microscope (TEM) Investigations:-

TEM micrographs of the CX6.5(MW)750 sample were recorded using High Resolution Transmission Electron Microscope (HRTEM) TECANI G ${ }^{2}$ spirit TWIN. The sample was prepared by mixing the powder with ethanol, and then subjected to sonication for 10 min., and placing a drop onto former-backed carbon coated copper grid. Transmission micrographs were obtained using accelerating voltage $120 \mathrm{kV}$, conducted by VELETA camera.

\section{Pore Texture Studies:-}

To evaluate the textural parameters of the xerogel samples under investigation, the adsorption / desorption isotherms of nitrogen at $77 \mathrm{~K}$ were constructed using NOVA 3000 Multi-Station High Speed Gas Sorption Analyzer (QuantaChrome Corporation), Version 6.07. Approximately (0.1- 0.2) grams of sample were originally out gassed at $523 \mathrm{~K}$ for about $5 \mathrm{~h}$. under a vacuum of about $1.3 \times 10^{-5} \mathrm{KPa}$. After cooling, the samples were kept in a $\mathrm{N}_{2}$ atmosphere and later evacuated with a drag pump. The results were expressed in relation to unit mass of out gassed CX. The true adsorption equilibrium checked at regular intervals, following it during long periods. The adsorption isotherms were analyzed to get various porous parameters: i) The BET-equation parameters (Brunauer et al., 1938): $\mathrm{S}_{\mathrm{BET}}$ (BETsurface area, $\left.\mathrm{m}^{2} \cdot \mathrm{g}^{-1}\right), \mathrm{C}_{\mathrm{BET}}$ (the constant $\mathrm{C}$ of the BET equation) and $\mathrm{V}_{\mathrm{P}(\text { total) }}$ (total pore volume, $\mathrm{cc}^{-1} \mathrm{~g}^{-1}$ ), and ii) The 
$\alpha_{\mathrm{S}}$-plot parameters (Sellés-Pérez and Martín-Martínez, 1991): $s_{t}^{\alpha}$ (total surface area, $\mathrm{m}^{2} \cdot \mathrm{g}^{-1}$ ), $s_{n}^{\alpha}$ (non-microporous surface area, $\mathrm{m}^{2} \cdot \mathrm{g}^{-1}$ ), $s_{\text {mic }}^{\alpha}$ (microporous surface area, $\mathrm{m}^{2} \cdot \mathrm{g}^{-1}$ ), $v_{o}^{\alpha}$ (micropore volume, $c \mathrm{cc} \cdot \mathrm{g}^{-1}$ ), $\bar{r}$ (mean pore radius, $\AA$ ) and $\mathrm{V}_{\text {meso }}$ (mesopore volume, cc. $\mathrm{g}^{-1}$ ).

\section{Methylene Blue Adsorption Studies:-}

A stock aqueous solution of MB (1000 ppm) was prepared. Other solutions of MB were prepared from this solution by dilution to the required concentration. The adsorption of MB was made by placing $50 \mathrm{mg}$ of each of powdered $\mathrm{CX}$, which was dried in an oven at $110^{\circ} \mathrm{C}$ for $2 \mathrm{~h}$, in a stopper Pyrex bottles containing a $50 \mathrm{ml}$ of dye solution. The bottles with their contents were shaken occasionally for $72 \mathrm{~h}$. at $25^{\circ} \mathrm{C}$. Preliminary experiments established that equilibrium times of $48 \mathrm{~h}$. were needed to determine solution adsorption isotherms for CXs. The supernatant liquid was removed and analyzed spectrophotometrically using a double beam computerized UV/Visible Scanning Spectrophotometer [type Shimadzu (UV-2101 PC)] and $\lambda_{\max }=662.5 \mathrm{~nm}$. The amount adsorbed was calculated from the difference between the initial and the equilibrium concentrations of MB in the aqueous solution (Girgis and El-Hendawy, 2002). The experimental error was about 5\%. Reproducibility was ensured by repeating the experiment under the same conditions.

\section{Results and Discussion:-}

\section{Physicochemical and Surface Chemistry Characteristics:-} Yield of Carbon Xerogel:-

Carbonization of the prepared OXs causes removal of the captured solvent, release of volatile matter including residual organic components and non cross linked organic chains, and volatilization of labile oxygen and hydrogen leading to an additional weight loss. This results in the formation of thermally stable nanostructured material formed mainly by carbon. The results of the \% yield (expressed as the ratio between the mass of CX and the mass of OX under different conditions) are summarized in Table (1). The results indicate the following: 1) The CX yield depends largely on the $\mathrm{R}-\mathrm{F}$ solution $\mathrm{pH}$ values. It increases continuously with increasing the $\mathrm{pH}$ value from 3.0 (46.6\%) up to $6.5(66.0 \%)$ then declines at $\mathrm{pH} 7.2(54.8 \%)$. 2) The CX yield depends also on the CT. As expected, as the CT was increased the yield was reduced. It decreases continuously from 72.0 to $60.0 \mathrm{wt} \%$ by increasing the $\mathrm{CT}$ from 600 to $800{ }^{\circ} \mathrm{C}$, which can be attributed to more and more release of oxygen and hydrogen, as well as a decrease in carbon content, with raising the CT. 3) The synthesis method largely affects the yield. MW induced synthesis method promotes the yield of CX by $10 \%$ compared to the conventional method (66.0 and $56.0 \%$, respectively). The higher CX yield of the microwave assisted method is a very important factor favors it over the conventional method.

\section{Elemental Analysis:-}

The results of elemental analysis of the CXs investigated are presented in Table (1). It can be observed that the content of elemental carbon, hydrogen and oxygen depends on the preparation conditions, as follows: 1) The content of carbon depends on the original $\mathrm{R}-\mathrm{F}$ solution $\mathrm{pH}$ value. It decreases very slightly with the increase of the $\mathrm{pH}$ value from $3.0(94.19 \%)$ to $5.0(94.11 \%)$, then continuously up to $\mathrm{pH} 7.2(87.24 \%)$. 2) The content of carbon, also, depends on the CT. As the CT was increased the content of carbon was decreased. It decreases linearly from 91.45 $\%$ to $81.45 \%$ by raising the CT from 600 to $800^{\circ} \mathrm{C}$. 3) Carbon content depends, also, on the synthesis method. The MW induced synthesis method shows a higher content of carbon compared to the conventional method ( $88.71 \%$ and $83.37 \%$, respectively).

\section{Slurry pH of the Investigated CXs Surfaces:-}

The $\mathrm{pH}$ value of a carbon surface represents the average effect of species of various strength and number, i.e. the average effect of both acidic and basic groups existing on the surface. As an indication of $\mathrm{pH}$ of the $\mathrm{CX}$ surface, the slurry $\mathrm{pH}$ of a $\mathrm{CX}$ suspension was measured. All values were obtained at the same conditions. The $\mathrm{pH}$ values of the investigated CXs surfaces are given in Table (2). As deduced from the $\mathrm{pH}$ values, the chemical nature of the CX surfaces is different. 1) The surface $\mathrm{pH}$ value depends largely on of the original $\mathrm{R}-\mathrm{F}$ solution $\mathrm{pH}$ value. It increases linearly with increasing the $\mathrm{pH}$ value from 3.0 up to 7.2. 2) The surface $\mathrm{pH}$ value is influenced also with the CT. As the $\mathrm{CT}$ was increased, the surface $\mathrm{pH}$ value was increased. It increases continuously from 6.04 to 7.02 by raising the CT from 600 to $800^{\circ} \mathrm{C}$. The acidic functional groups are easily decomposed with raising the CT (Bansal and Goyal, 2005) leading to a decrease of the acidity of the prepared CXs and, as a result, an increase of the $\mathrm{pH}$ value. 3) The chemical nature of the CX surfaces depends on the synthesis method. The MW induced synthesis method shows slightly acidic character compared to the conventional method ( $\mathrm{pH}=6.70$ and 7.21 , respectively). 
Table 1:- Yield (wt.\%), elemental analysis and average particle size of the investigated CX samples.

\begin{tabular}{|c|c|c|c|c|c|c|c|c|}
\hline \multirow{3}{*}{$\begin{array}{c}\text { Sample } \\
\text { Notation }\end{array}$} & \multirow{3}{*}{$\%$ Yield } & \multicolumn{6}{|c|}{ Elemental analysis } & \multirow{3}{*}{ 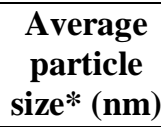 } \\
\hline & & \multicolumn{3}{|c|}{ wt. \% of the element } & \multicolumn{3}{|c|}{ Atomic content } & \\
\hline & & $\mathbf{C}$ & $\mathbf{H}$ & $\mathbf{O}$ & $\mathbf{C}_{\text {at }}$ & $\mathbf{H}_{\mathrm{at}}$ & $\mathbf{O}_{\mathrm{at}}$ & \\
\hline \multicolumn{9}{|c|}{ Effect of Initial pH } \\
\hline CX3.0(MW)750 & 46.6 & 94.19 & 2.28 & 3.53 & 7.85 & 2.28 & 0.22 & 9.0 \\
\hline CX5.0(MW)750 & 49.6 & 94.11 & 1.34 & 4.55 & 7.84 & 1.34 & 0.28 & 8.0 \\
\hline CX6.0(MW)750 & 51.8 & 92.63 & 1.43 & 5.94 & 7.72 & 1.43 & 0.37 & 9.0 \\
\hline CX6.5(MW)750 & 66.0 & 88.71 & 3.04 & 8.25 & 7.39 & 3.04 & 0.51 & 5.9 \\
\hline CX7.2(MW)750 & 54.8 & 87.24 & 2.59 & 10.16 & 7.27 & 2.59 & 0.63 & 6.4 \\
\hline \multicolumn{9}{|c|}{ Effect of CT } \\
\hline CX6.5(MW)600 & 72.0 & 91.45 & 2.88 & 5.67 & 7.62 & 2.88 & 0.35 & 8.0 \\
\hline CX6.5(MW)700 & 68.6 & 87.41 & 4.34 & 8.25 & 7.28 & 2.67 & 0.51 & 9.7 \\
\hline CX6.5(MW)750 & 66.0 & 88.71 & 1.37 & 9.92 & 7.39 & 3.04 & 0.08 & 5.9 \\
\hline CX6.5(MW)800 & 60.0 & 81.45 & 2.98 & 15.29 & 6.79 & 2.97 & 0.96 & 9.0 \\
\hline \multicolumn{9}{|c|}{ Effect of synthesis method } \\
\hline CX6.5(C)750 & 56.0 & 83.37 & 4.00 & 12.63 & 6.95 & 4.00 & 0.79 & 6.2 \\
\hline CX6.5(MW)750 & 66.0 & 88.71 & 1.37 & 9.92 & 7.39 & 3.04 & 0.09 & 5.9 \\
\hline
\end{tabular}

*Calculated by Scherrer formula.

\section{Surface acidic and basic active sites:-}

The chemical properties of the investigated CXs surfaces were assessed by neutralization with bases of various strengths $\left(\mathrm{NaHCO}_{3}, \mathrm{Na}_{2} \mathrm{CO}_{3}\right.$ and $\left.\mathrm{NaOH}\right)$ and $\mathrm{HCl}$. According to Boehm (Boehm, 2002), the bases consumption can be described in the presence of surface acidic groups with various strength while the acid uptake characterizing the carbon surface basicity. Only the strong acidic groups (carboxyl) can be neutralized by $\mathrm{NaHCO}_{3}\left(\mathrm{pKa}^{2} 6.37\right)$, whereas $\mathrm{Na}_{2} \mathrm{CO}_{3}(\mathrm{pKa}=10.25)$ titrates carboxyl and lactones. $\mathrm{NaOH}(\mathrm{pKa}=15.74)$ neutralizes carboxyl, lactones and phenolic (hydroxyl) groups. The results of the acid-base titration to determine the surface acidic and basic active sites by the Boehm method are shown in Table (2). Total surface acidic sites included phenolic, lactonic and carboxylic sites, whereas basic sites may include chromene-, pyrone-, and quinone-type structures (Boehm, 2002). The most distinguishing feature of these CXs is the co-existence of the acidic and basic sites; i.e. the representation of all types of surface functional groups. Thus, these CXs are amphoteric in nature. The concentration of the surface acidic and basic active sites depends on the CX synthesis conditions. The analysis of the data given in Table (2) provided the following: 1) The surface acidic and basic active sites depend largely on the original $\mathrm{R}-\mathrm{F}$ solution $\mathrm{pH}$ value. The total surface acidic sites decrease linearly from 2.37 to $1.00 \mathrm{meq} . \mathrm{g}^{-1}$, whereas the total surface basic sites increase continuously from 0.50 to $1.25 \mathrm{meq} . \mathrm{g}^{-1}$ with raising the $\mathrm{pH}$ value from 3.0 up to 7.2 . Thus, increasing the initial $\mathrm{pH}$ from 3.0 to 7.2 (i.e. increasing the amount of basic catalyst) results in a decrease in the acidic function groups and an increase in the basic function groups. 2) The surface acidic and basic active sites depend largely on the CT. The total surface acidic sites decrease from 1.30 to $0.85 \mathrm{meq} . \mathrm{g}^{-1}$, whereas the total surface basic sites increases from 0.60 to 1.22 meq. $\mathrm{g}^{-1}$ by raising the $\mathrm{CT}$ from 600 to $800{ }^{\circ} \mathrm{C}$. The decrease in the surface acidic groups by increasing the CT indicates that these groups are thermally unstable, whereas the surface basic groups are stable up to $800^{\circ} \mathrm{C}$, as reported by Bansal and Goyal (Bansal and Goyal, 2005). 3) The surface acidic and basic active sites depend on the synthesis method. The MW induced synthesis method shows more total surface acidic and basic sites compared to the conventional method. It is possible that, during the microwave synthesis, some secondary reactions take place producing a higher cross linked organic gel with more stable oxygen functional groups (Caddick, 1995; Le Van and Gourdenne, 1987). These oxygen groups will remain after the carbonization process in a higher extent than in the CXs prepared conventionally. So, to develop more functional groups on the CX surface, it is advisable to use MW assisted synthesis method. 
Table 2:- $\mathrm{pH}$ values of the investigated CXs surfaces, and number of surface species (meq. $\mathrm{g}^{-1}$ ) obtained from Boehm titration.

\begin{tabular}{|c|c|c|c|c|c|c|c|}
\hline Sample notation & $\mathbf{p H}$ & $\begin{array}{c}\text { Carboxylic } \\
\text { sites }\end{array}$ & $\begin{array}{c}\text { Lactonic } \\
\text { sites }\end{array}$ & $\begin{array}{c}\text { Phenolic } \\
\text { sites }\end{array}$ & $\begin{array}{c}\text { Total } \\
\text { Acidic sites }\end{array}$ & $\begin{array}{c}\text { Basic } \\
\text { sites }\end{array}$ & $\begin{array}{c}\text { Total } \\
\text { surface coverage }\end{array}$ \\
\hline \multicolumn{7}{|c|}{ Effect of pH } \\
\hline CX3.0(MW)750 & 2.65 & 0.51 & 0.44 & 1.42 & 2.37 & 0.50 & 2.87 \\
\hline CX5.0(MW)750 & 4.76 & 0.32 & 0.30 & 1.13 & 1.75 & 0.80 & 2.55 \\
\hline CX6.0(MW)750 & 5.89 & 0.27 & 0.25 & 0.73 & 1.25 & 1.20 & 2.45 \\
\hline CX6.5(MW)750 & 6.70 & 0.25 & 0.24 & 0.72 & 1.21 & 1.20 & 2.41 \\
\hline CX7.2(MW)750 & 7.31 & 0.20 & 0.16 & 0.64 & 1.00 & 1.25 & 2.25 \\
\hline \multicolumn{7}{|c|}{ Effect of CT } \\
\hline CX6.5(MW)600 & 6.04 & 0.09 & 0.76 & 0.45 & 1.30 & 0.60 & 1.90 \\
\hline CX6.5(MW)700 & 6.20 & 0.13 & 0.48 & 0.66 & 1.27 & 1.00 & 2.27 \\
\hline CX6.5(MW)750 & 6.70 & 0.25 & 0.24 & 0.72 & 1.21 & 1.20 & 2.41 \\
\hline CX6.5(MW)800 & 7.02 & 0.29 & 0.12 & 0.75 & 0.85 & 1.22 & 2.07 \\
\hline \multicolumn{7}{|l|}{ Effect of Synthesis method } \\
\hline CX6.5(C)750 & 7.21 & 0.09 & 0.18 & 0.37 & 0.64 & 0.85 & 1.49 \\
\hline CX6.5(MW)750 & 6.70 & 0.25 & 0.24 & 0.72 & 1.21 & 1.20 & 2.41 \\
\hline
\end{tabular}

Identification of surface functional groups by FTIR:-

This study provides qualitative information on the chemical structure of the investigated CX surface. Figure (2) displays the FTIR absorption spectra obtained for the CX samples prepared under different conditions. It is clear that these samples have nearly the same absorption peaks, which ensures the fact that most porous carbon materials are characterized by the presence of carboxylic, phenolic hydroxyl, carbonyl and lactone groups (Shafeeyan et al., 2010). However the difference in the relative intensities of the respective bands indicate that some differences are present in the chemical structure of these samples due to the different preparation methods and conditions. Analysis of the absorption bands for the CX6.5(MW)750 sample, for example [c.f. Figure (2 (a) )], shows the following: 1) The absorptions displayed in the range $3688-3082 \mathrm{~cm}^{-1}$ as broad band with maximum absorption centered at 3400 $\mathrm{cm}^{-1}$ is ascribed to $\mathrm{O}-\mathrm{H}$ stretching vibrations $[\mathrm{v}(\mathrm{O}-\mathrm{H})]$ due to the existence of surface hydroxyl groups, with participation of adsorbed water. The asymmetry of this band at lower wave number indicates the presence of strong hydrogen bonds (O'reilly and Mosher, 1983). 2) The weak absorptions displayed in the range $2997-2750 \mathrm{~cm}^{-1}$ as broad band centered at $2918 \mathrm{~cm}^{-1}$ are ascribed to $\mathrm{C}-\mathrm{H}$ symmetric and asymmetric stretching of some aliphatic species on the sample, i.e. methyl and methylene groups (Li et al., 2013). 3) The absorptions displayed in the range $1360-1138 \mathrm{~cm}^{-1}$ with a maximum centered at $1200 \mathrm{~cm}^{-1}$ can be assigned to $\mathrm{C}-\mathrm{O}$ stretching in alcohols, phenols, ethers and esters (Figueiredo et al., 1999). 4) The absorption bands displayed in the range $1695-1397 \mathrm{~cm}^{-1}$ with maximum absorptions centered at 1600 and $1460 \mathrm{~cm}^{-1}$ can be attributed to the stretching vibrations of the $\mathrm{C}=\mathrm{O}$ moieties in carboxylic and lactone systems, overlapping the $\mathrm{C}=\mathrm{C}$ stretching vibrations of aromatic rings of quinone and keto-enol groups (Figueiredo et al., 1999). The results obtained in the present FTIR absorption studies are in agreement with those obtained by the Boehm-titration method. 


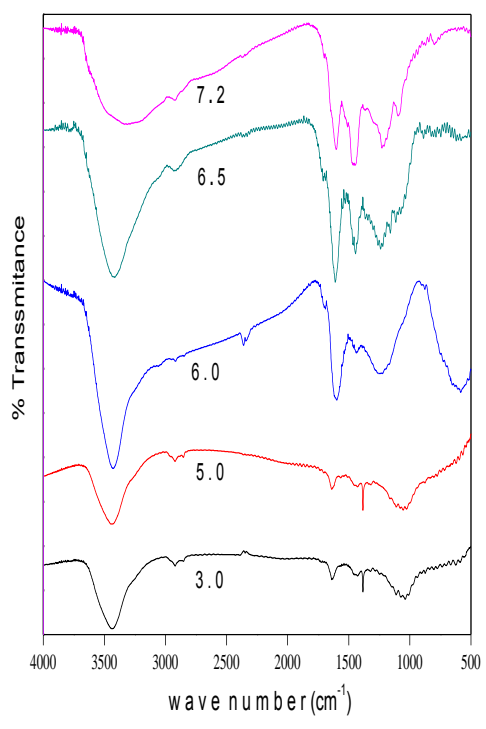

(a)

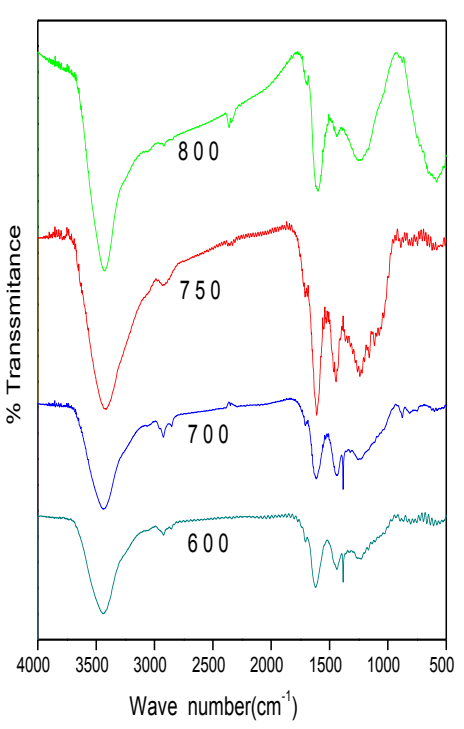

(b)

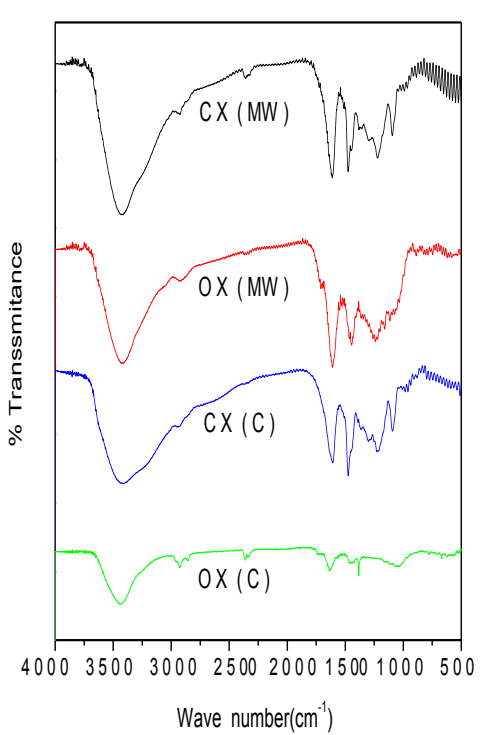

(c)

Fig. 2:- FTIR spectra of the CX samples obtained under different conditions: (a) different R-F solutions pH values,

(b) different CTs and (c) different synthesis methods.

\section{XRD Analysis:-}

The X-ray diffraction patterns of the CX samples obtained under different conditions are given in Fig.3 (a-c), whereas those of the OX samples are represented in Fig.3 (d). The peak located at 25.3 can be assigned to the maximum diffraction of graphitic carbon (002) plane (Yoon et al., 2005). Thus, the XRD results indicate that all CX samples are crystalline in nature and consists of a single phase with a graphite structure, as reported also by Oyedoh et al. (Oyedoh et al., 2013). On the other hand, the OX samples are semi crystalline in nature, as shown in figure 3(d). The average crystallite size of the CX samples obtained under different conditions are given in Table (1). It can be observed that the average crystallite size is in the nanoscale range between 5.9 and $9.7 \mathrm{~nm}$.

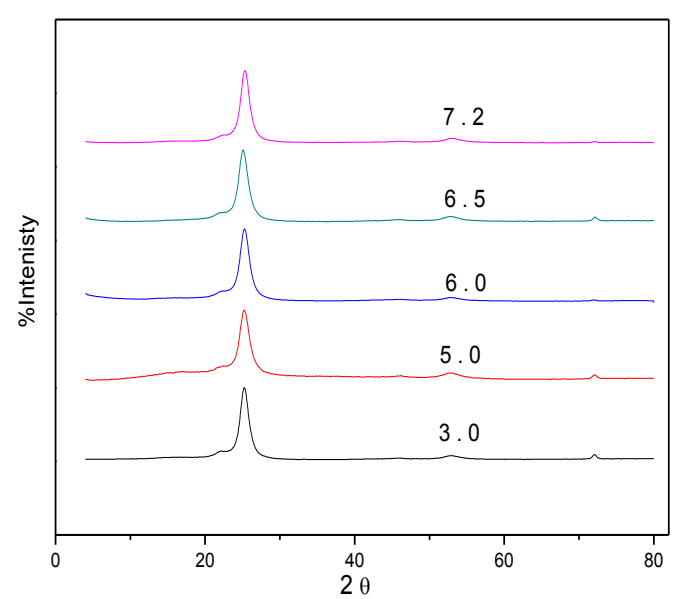

(a)

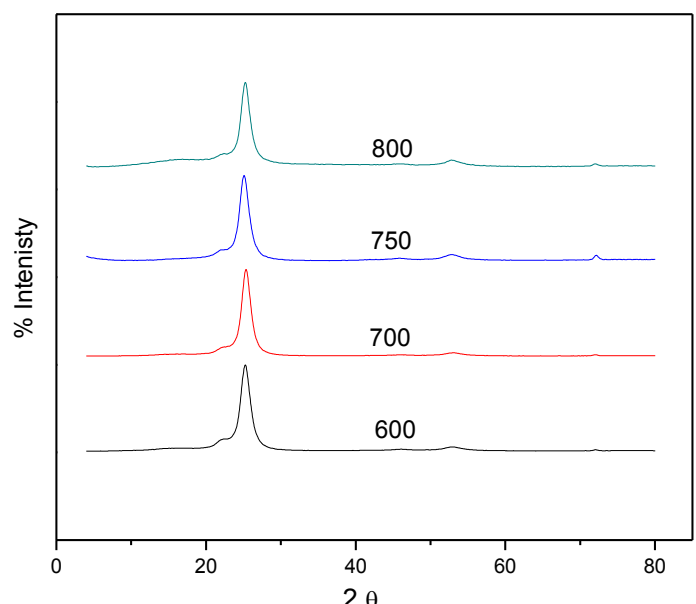

(b) 

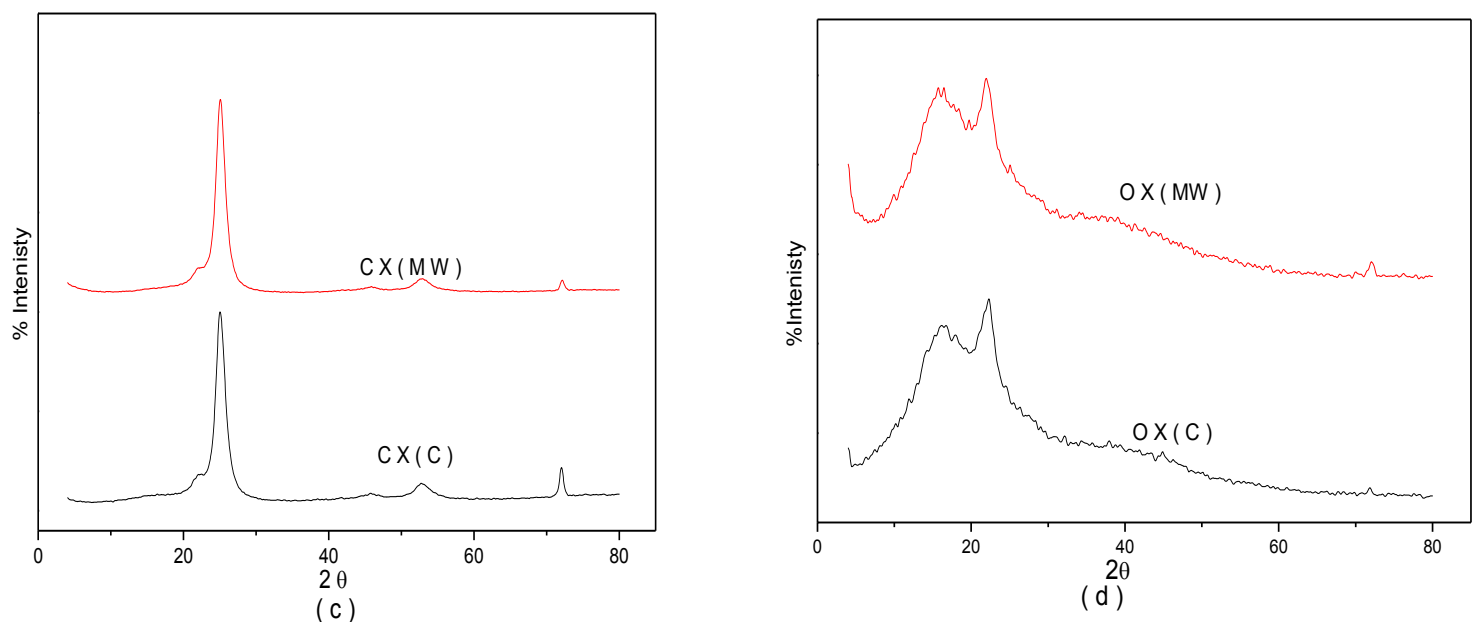

Fig. 3:- XRD patterns recorded for the CX samples obtained under different conditions:(a) different R-F solutions $\mathrm{pH}$ values, (b) different CTs and (c) different synthesis methods, also for the OX samples prepared with different methods (d).

\section{Scanning Electron Microscope (SEM) Observations:-}

The surface features of a selected sample [CX6.5(MW)750] was examined by SEM for structure, degree of uniformity and the development of porosity. The SEM results at high magnification, Figure (4(b)), confirm the fine and nanostructured nature of the CX under consideration with fine nanosized grains, wide interparticle voids, interconnected particles with irregular shapes. A uniform pore distribution all over the surface was also observed.

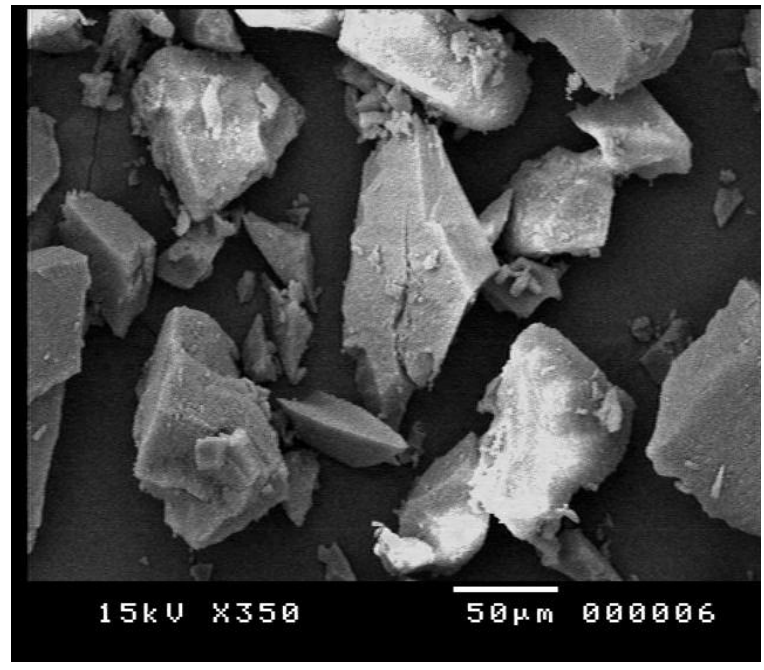

(a)

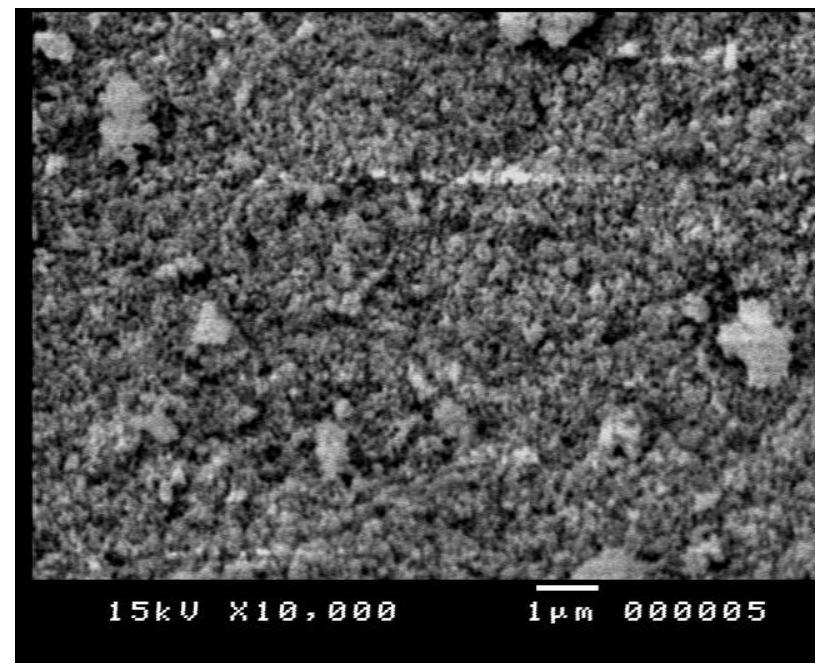

(b)

Fig. 4:- SEM micrographs of the CX6.5(MW)750 sample at two different magnifications.

Transmission Electron Microscope (TEM) Investigations:-

The TEM micrographs in Figure (5) at two different magnifications confirms the fine and nanostructured nature of the CX sample. They show distinctly beads of pearl nature of the very fine particles $(<50 \mathrm{~nm})$ and the pores which are originated by the interconnection of CX particles. 

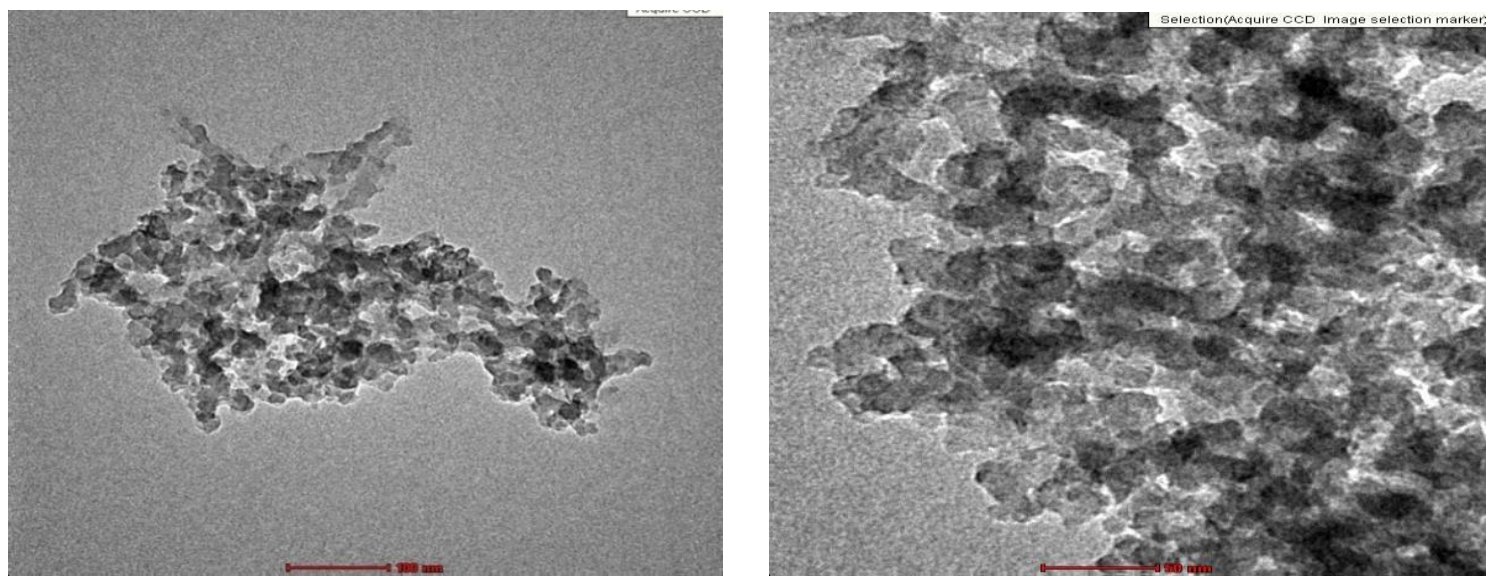

Fig. 5:- TEM micrographs of the CX6.5(MW)750 sample at two different magnifications.

\section{Pore Texture characteristics:-}

The sorption isotherms of $\mathrm{N}_{2}$ at $77 \mathrm{~K}$ for the $\mathrm{CX}$ samples synthesized at different initial R-F solutions $\mathrm{pH}$ values are given in Fig. (6 (a)),
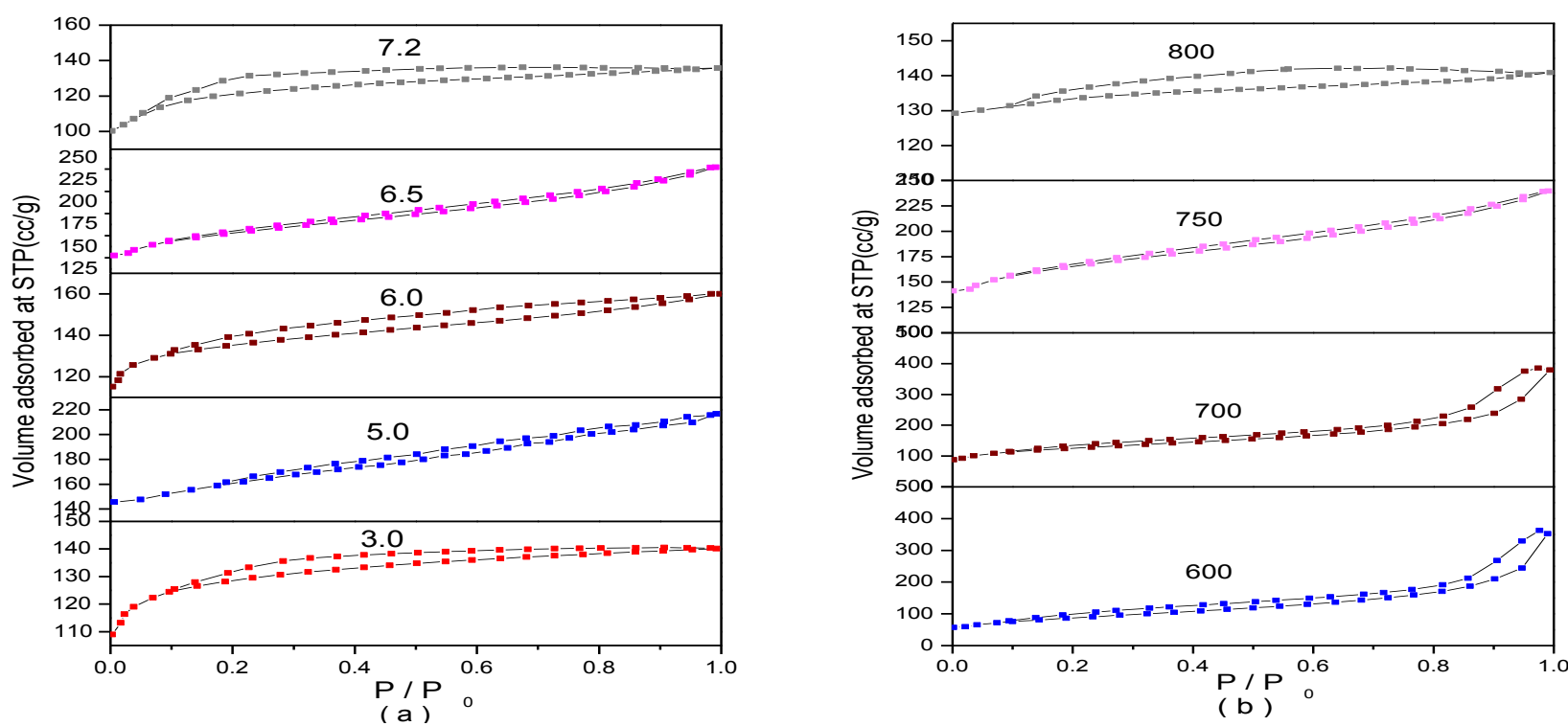


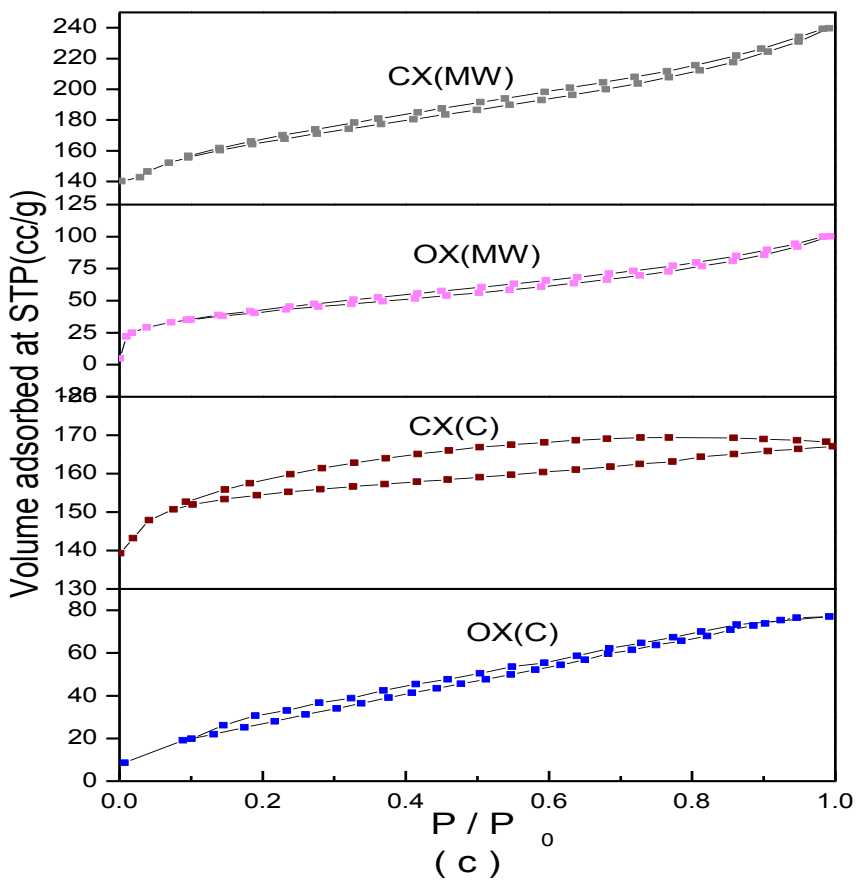

Fig. 6:- Nitrogen sorption isotherms at $77 \mathrm{~K}$ for the CXs obtained under different conditions: (a) different R-F solutions $\mathrm{pH}$ values, (b) different CTs and (c) different synthesis methods.

whereas their $\alpha_{S}$-plots are shown in Fig. (7 (a)). As shown in Fig. (6 (a)), the type of the isotherm depends largely on the R-F pH value. The adsorption isotherm of the CX3.0(MW)750 sample exhibits type I feature in the BDDT classification (Brunauer et al., 1940) with very sharp "knee" at the low pressures end (P/Po < 0.02) and very little of the type II features at relative higher pressures. This indicates a developed microporosity with some mesoporosity and capillary condensation (Pradhan and Sandle, 1999). The type II features increase with raising the R-F pH value. The isotherm of the CX6.5(MW)750 sample exhibits type II feature which indicates the more development of mesoporosity, i.e. the presence of mixed micro- and mesoporosity.

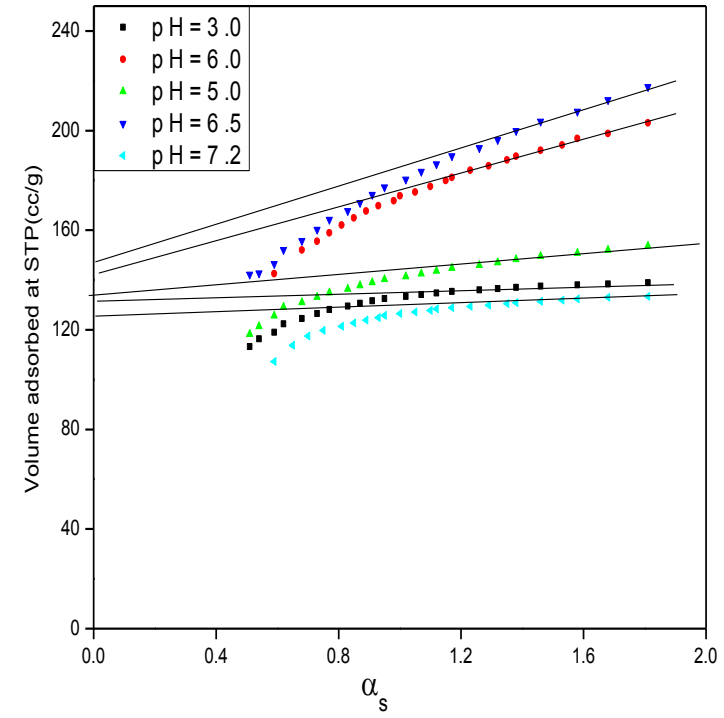

(a)

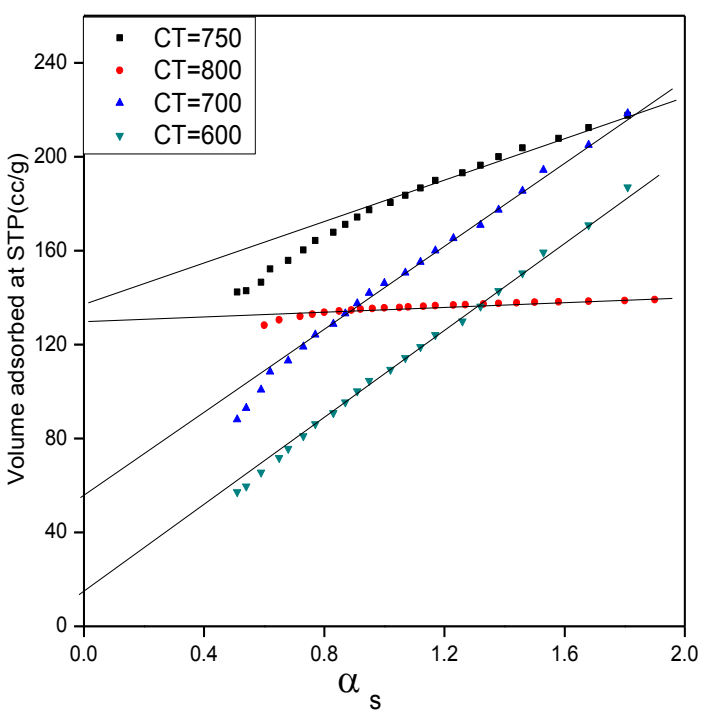

(b) 


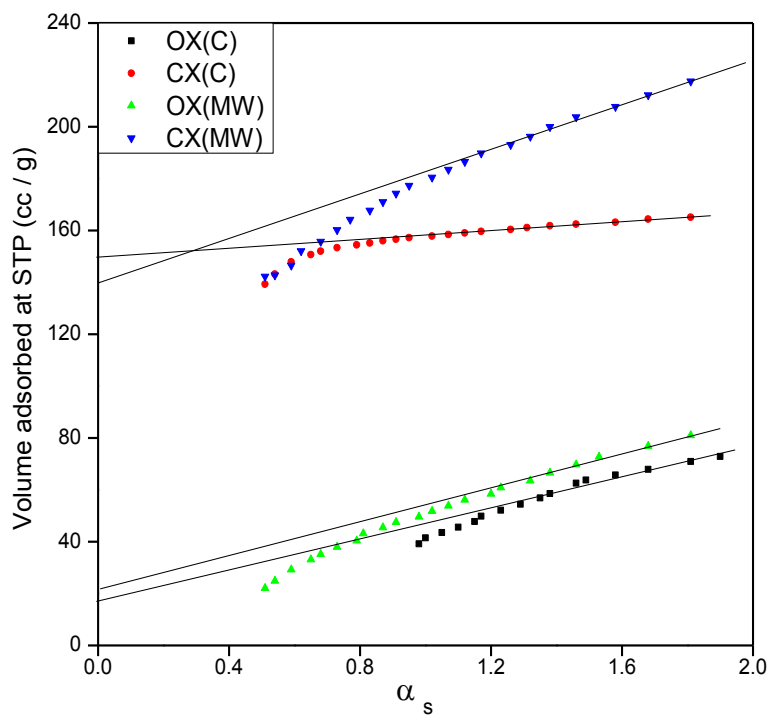

(c)

Fig. 7:- $\alpha_{S}$-Plots for the CXs obtained under different conditions: (a) different R-F solutions pH values, (b) different CTs and (c) different synthesis methods.

The $\alpha_{S}$-plots complement the observations obtained from the sorption isotherms, as these plots exhibit features of the type (f) of the $\alpha_{S}$-plots classification (Sellés-Pérez and Martín-Martínez, 1991). The $\alpha_{S}$ plot in (f) is derived from a Type I isotherm or composite of Type I and II isotherms; here micropore filling is followed by multilayer adsorption on a small external surface (Carrott et al., 1987).The evaluated texture characteristics obtained from the BET-equation and $\alpha_{s}$-plots are summarized in Table (3). A comparative representation of the data for total surface area $\left(s_{t}^{\alpha}\right)$, microspore surface area $\left(s_{\text {mic }}^{\alpha}\right)$ and non microporous surface area $\left(s_{n}^{\alpha}\right)$ obtained from the $\alpha_{S}$-plots for these CX samples, prepared at different initial R-F solution $\mathrm{pH}$ values, are given in Fig. (8 (a)). The following can be observed: 1) The evaluated texture parameters of the CXs prepared under different $\mathrm{R}-\mathrm{F} \mathrm{pH}$ values indicate that these CXs are in general microporous $\left(s_{\text {mic }}^{\alpha} / s_{t}^{\alpha}\right.$ in the range 72.0-97.0\%) with some mesoporosity $\left(s_{n}^{\alpha} / s_{t}^{\alpha}\right.$ in the range 3.0-28.0 \% ). 2) As the $\mathrm{pH}$ increased from 3.0 to 6.5, the surface area increased from 484 to $622 \mathrm{~m}^{2} \cdot \mathrm{g}^{-1}$, then decreased sharply to 412 at $\mathrm{pH}$ 7.2. Increasing the $\mathrm{pH}$ value from 3.0 to 6.0 leads to a greater cross-linking of the already formed clusters due to lower concentration of protons in the media which resulted in a more porous polymeric structure (Zanto et al., 2002b). On the other hand, increasing the $\mathrm{pH}$ up to 7.2 causes the condensation reaction to be hindered leading to less cross-linking of the structures and resulting in a much weaker porous structure than at lower $\mathrm{pH}$ value. 3) The CX6.5(MW)750 sample possesses the highest total and micropore surface area parameters. It has mixed micro- and mesoporosity. The mesopore volume for this sample is $\sim 43 \%$ of the total pore volume.

The sorption isotherms of $\mathrm{N}_{2}$ at $77 \mathrm{~K}$ for the $\mathrm{CX}$ samples synthesized at fixed $\mathrm{R}-\mathrm{F} \mathrm{pH}$ value $(\mathrm{pH}=6.5)$ and different CTs are given in Fig.(6 (b)), whereas their $\alpha_{s}$-plots are shown in Fig.(7 (b)). These isotherms exhibit type II features in the BDDT classification with sharp "knee" at the low pressures end, which indicates carbons with mixed microand mesoporosity. The evaluated texture characteristics are also summarized in Table (3). A comparative representation of the data for $s_{t}^{\alpha}, s_{m i c}^{\alpha}$ and $s_{n}^{\alpha}$ obtained from the $\alpha_{S}$-plots for these samples are given in Fig. (8 (b)). The following can be observed: 1) The texture parameters of the $\mathrm{CX}$ samples prepared at fixed $\mathrm{R}-\mathrm{F} \mathrm{pH}$ value $(\mathrm{pH}=$ 6.5) and different CTs reflect that raising the CT is accompanied by a continuous development in the total surface area $\left(s_{t}^{\alpha}\right)$ with a maximum value at $750^{\circ} \mathrm{C}$. 2) The microspore surface area $\left(S_{\text {mic }}^{\alpha}\right)$ increases continuously with raising the $\mathrm{CT}$ up to $800^{\circ} \mathrm{C}$. The $s_{m i c}^{\alpha} / s_{t}^{\alpha}$ value increases from $17.7 \%$ to $98.2 \%$ by raising the $\mathrm{CT}$ from $600^{\circ} \mathrm{C}$ up to $800^{\circ} \mathrm{C}$. Also, the $\mathrm{V}_{\text {mic }} / \mathrm{V}_{\mathrm{p}}$ (total) value increases continuously from $5.1 \%$ to $93.6 \%$. 3) The non-microporous surface area $\left(s_{n}^{\alpha}\right)$ decreases sharply with raising the $\mathrm{CT}$ up to $800^{\circ} \mathrm{C}$. 4) When the pyrolysis temperature increases, the micropore volume first increases (due to the opening of the closed pores and a widening of the narrowest micropores already present), then passes through a maximum $\left(0.212 \mathrm{~cm}^{3} \cdot \mathrm{g}^{-1}\right)$ at $750{ }^{\circ} \mathrm{C}$ and finally decreases to reach $\left(0.203 \mathrm{~cm}^{3} \cdot \mathrm{g}^{-1}\right)$ at $800^{\circ} \mathrm{C}$. 


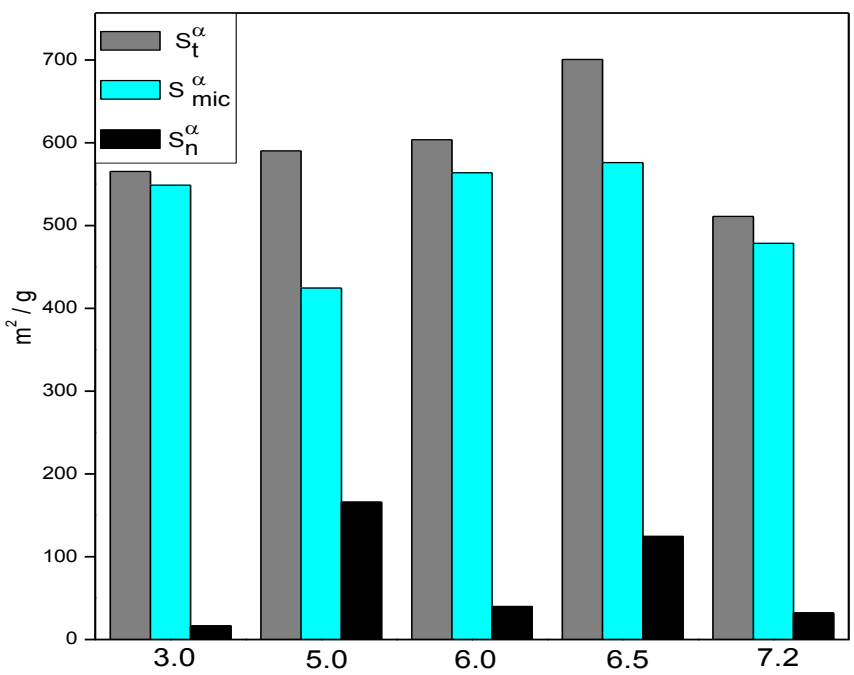

(a)

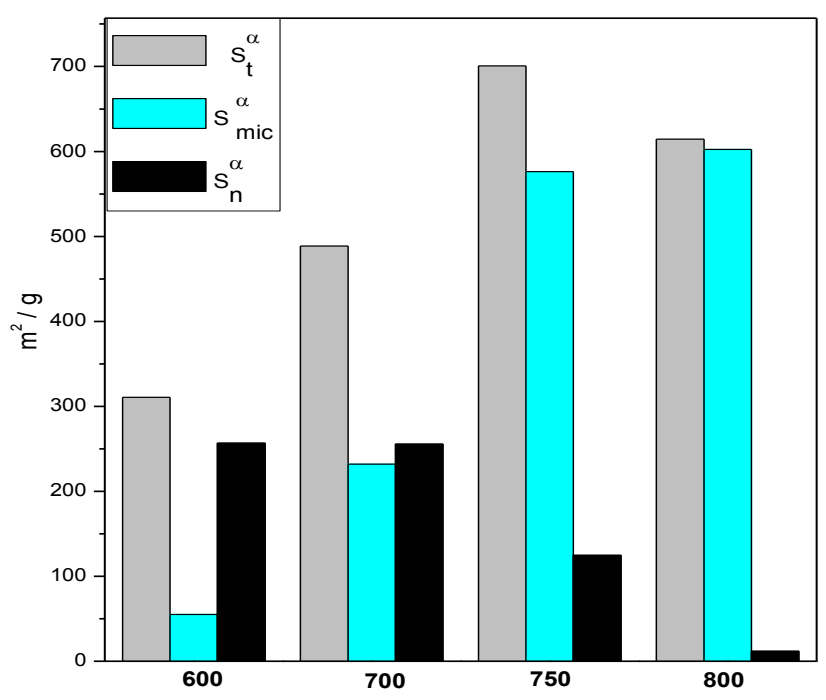

(b)

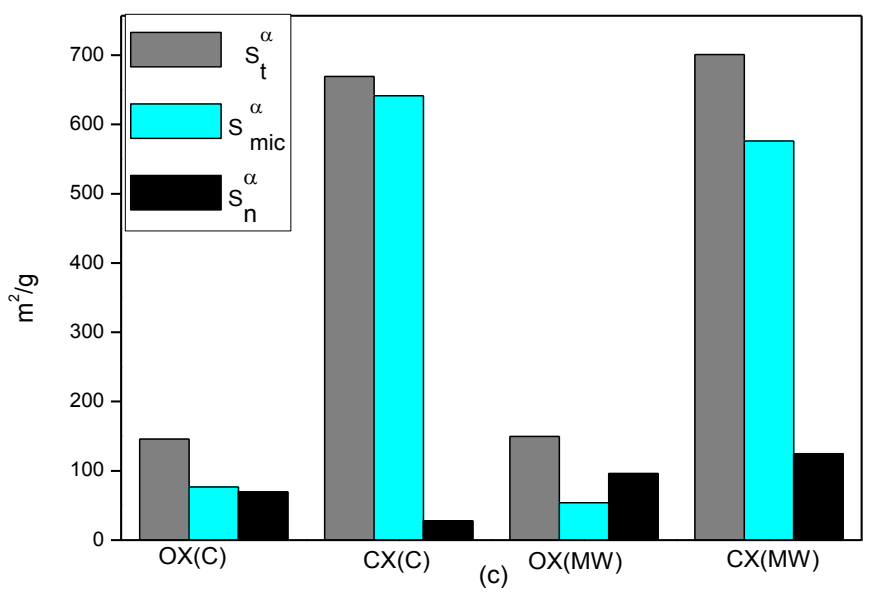

Fig. 8:- A comparative representation of the data for total surface area $\left(s_{t}^{\alpha}\right)$; microporous surface area $\left(s_{\text {mic }}^{\alpha}\right)$; and non- microporous surface area $\left(s_{n}^{\alpha}\right)$; obtained from the $\alpha_{S}-$ plots for the CXs obtained under different conditions:

(a) different R-F solutions pH values, (b) different CTs and (c) different synthesis methods.

The sorption isotherms of $\mathrm{N}_{2}$ at $77 \mathrm{~K}$ for the $\mathrm{OX}$ and $\mathrm{CX}$ samples synthesized by the two different methods are given in Fig. $\left(6\right.$ (c)), whereas their $\alpha_{S}$-plots are shown in Fig. (7 (c)). As shown in Fig. (6 (c)), the type of the isotherm of the organic or carbon xerogel depends on the synthesis methods. The adsorption isotherm of the OX6.5(C) and CX6.5(C)750 samples exhibits type I feature in the BDDT classification with sharp "knee" at the low pressures end and very little of the type II features at relative higher pressures $\left(>0.65 \mathrm{P} / \mathrm{P}^{\circ}\right)$. This indicates a developed microporosity with some mesoporosity and capillary condensation. On the other hand, the isotherm of the OX6.5(MW) sample exhibits type II feature which indicates the presence of mixed micro- and mesoporosity. The isotherm of the CX6.5(MW)750 sample preserves the type II feature with sharp "knee" at the low pressures end $(\mathrm{P} / \mathrm{Po}<0.05)$ indicating also a carbon with micro- and mesoporous structure. 
Table 3:- Porous characteristics of the organic and carbon xerogels under different synthesis conditions

\begin{tabular}{|c|c|c|c|c|c|c|c|c|c|c|c|c|c|}
\hline \multirow{2}{*}{$\begin{array}{c}\text { Sample } \\
\text { notation }\end{array}$} & & & & \multicolumn{6}{|c|}{$\alpha_{S}-$ plots } & \multirow{2}{*}{$\begin{array}{l}S_{m i c}^{\alpha} \\
/ S_{t}^{\alpha} \\
(\%)\end{array}$} & \multirow{2}{*}{$\begin{array}{l}S_{n}^{\alpha} / \\
S_{t}^{\alpha} \\
(\%)\end{array}$} & \multirow{2}{*}{$\begin{array}{c}\mathrm{V}_{\text {mid }} \\
\mathrm{V}_{\mathrm{p} \text { (total) }} \\
(\%)\end{array}$} & \multirow{2}{*}{$\begin{array}{c}\mathrm{V}_{\text {meso }} \\
\mathrm{V}_{\mathrm{p} \text { (total) }} \\
(\%)\end{array}$} \\
\hline & $\begin{array}{c}\mathrm{S}_{\mathrm{BET}} \\
\left(\mathrm{m}^{2} / \mathrm{g}\right)\end{array}$ & $\mathrm{C}_{\mathrm{BET}}$ & $\begin{array}{l}\mathrm{V}_{\mathrm{P}(\mathrm{total})} \\
\text { (cc/g) }\end{array}$ & $\begin{array}{c}S_{t}^{\alpha} \\
\left(\mathrm{m}^{2} / \mathrm{g}\right)\end{array}$ & $\begin{array}{c}S_{n}^{\alpha} \\
\left(\mathrm{m}^{2} / g\right)\end{array}$ & $\begin{array}{c}\mathrm{S}_{\text {mic }}^{\alpha} \\
\left(\mathrm{m}^{2} / \mathrm{g}\right)\end{array}$ & $\begin{array}{c}\mathrm{V}_{0}^{\alpha} \\
\text { (cc/g) }\end{array}$ & $\begin{array}{c}\overline{1} \\
(\AA)\end{array}$ & $\begin{array}{l}\mathrm{V}_{\text {meso }} \\
(\mathrm{cc} / \mathrm{g})\end{array}$ & & & & \\
\hline \multicolumn{14}{|c|}{ Effect of pH } \\
\hline CX3.0(MW)750 & 484 & 1455 & 0.217 & 566 & 17 & 549 & 0.198 & 7.6 & 0.019 & 97.0 & 3.0 & 91.2 & 8.8 \\
\hline CX5.0(MW)750 & 498 & 1285 & 0.374 & 590 & 165 & 425 & 0.177 & 12.6 & 0.197 & 72.0 & 28.0 & 47.3 & 52.7 \\
\hline CX6.0(MW)750 & 513 & 567 & 0.247 & 604 & 40 & 564 & 0.198 & 9.1 & 0.049 & 93.4 & 6.6 & 80.2 & 19.8 \\
\hline CX6.5(MW)750 & 622. & 368 & 0.370 & 701 & 125 & 576 & 0.212 & 10.6 & 0.158 & 82.2 & 17.8 & 57.3 & 42.7 \\
\hline CX7.0(MW)750 & 412 & 155 & 0.210 & 511 & 32 & 479 & 0.177 & 8.2 & 0.033 & 93.7 & 6.3 & 84.3 & 15.7 \\
\hline \multicolumn{14}{|c|}{ Effect of CT } \\
\hline CX6.5(MW)600 & 308 & 256 & 0.545 & 311 & 256 & 55 & 0.028 & 7.6 & 0.517 & 17.7 & 82.3 & 5.1 & 94.9 \\
\hline CX6.5(MW)700 & 449 & 410 & 0.586 & 489 & 257 & 232 & 0.081 & 23.9 & 0.505 & 47.4 & 52.6 & 13.8 & 86.2 \\
\hline CX6.5(MW)750 & 622 & 368 & 0.370 & 701 & 125 & 576 & 0.212 & 10.6 & 0.158 & 82.2 & 17.8 & 57.3 & 42.7 \\
\hline CX6.5(MW)800 & 433 & 82 & 0.217 & 614 & 11 & 603 & 0.203 & 7.06 & 0.014 & 98.2 & 1.8 & 93.6 & 6.4 \\
\hline \multicolumn{14}{|c|}{ Effect of synthesis method } \\
\hline OX6.5(C) & 144 & 1179 & 0.119 & 146 & 69 & 77 & 0.041 & 19.5 & 0.078 & 52.7 & 47.3 & 34.5 & 65.5 \\
\hline OX6.5(MW) & 144 & 215 & 0.155 & 150 & 96 & 54 & 0.003 & 2.07 & 0.152 & 36.0 & 64.0 & 1.9 & 98.1 \\
\hline CX6.5(C)750 & 541 & 449 & 0.259 & 669 & 28 & 641 & 0.228 & 7.73 & 0.031 & 95.8 & 4.2 & 88.0 & 12.0 \\
\hline CX6.5(MW)750 & 622 & 368 & 0.370 & 701 & 125 & 576 & 0.212 & 10.6 & 0.158 & 82.2 & 17.8 & 57.3 & 42.7 \\
\hline
\end{tabular}

The $\alpha_{\mathrm{S}}$-plots complement the observation obtained from the sorption isotherms. For the OX6.5(C) and CX6.5(C)750 samples, these plots exhibit features of the type (f) of the $\alpha_{S}$-plots classification, where the micropore filling is followed by multilayer adsorption on a small external surface. On the other hand, the OX6.5(MW) and CX6.5(MW)750 samples exhibit features of the $\alpha-2$ type of the $\alpha_{S}$ plots classification, indicating developed carbon microporosity with some mesoporosity.

The evaluated texture characteristics obtained from the BET-equation and $\alpha_{S}$-plots are summarized also in Table (3), which reflects that the organic and carbon xerogels pore texture depends on the synthesis method. A comparative representation of the data for $s_{t}^{\alpha}, s_{m i c}^{\alpha}$ and $s_{n}^{\alpha}$ obtained from the $\alpha_{\mathrm{S}}$-plots for the organic and carbon xerogels under conventional and MW synthesis methods are given in Fig.(8 (c)).The following can be observed: 1) Comparing the texture parameters of the OXs [OX6.5(C) and OX6.5(MW) samples] with those of the corresponding CXs [CX6.5(C)750 and CX6.5(MW)750 samples, respectively], reflect that the carbonization process is accompanied by a drastic development in these parameters. 2) The texture parameters of the OX6.5(C) and OX6.5 (MW) samples show that an OX with slightly more developed total surface area and lower microporosity is obtained by the MW induced synthesis method. The OX6.5(MW) sample has predominantly non-microporous character. The non-microporous surface area $\left(s_{n}^{\alpha}\right)$ is more than $64.0 \%$ of the total surface area $\left(s_{t}^{\alpha}\right)$ for this sample. This percentage decreases sharply from 64.0 to $\sim 17.8 \%$ by carbonization at $750{ }^{\circ} \mathrm{C}$. 3) The texture parameters of the CX6.5(C)750 and CX6.5(MW)750 samples reflect that a CX with more developed porosity (17.8\%) is obtained by the MW induced synthesis method rather than by the conventional synthesis one (4.2\%). 4) The texture parameters of the CX6.5(C)750 sample reflect that the conventional synthesis method produces essentially microporous carbon with wide microporosity $(95.8 \%)$ and containing some mesopores $(4.2 \%)$. On the other hand, the parameters of the CX6.5(MW)750 sample indicate that the MW induced synthesis method produces, also, microporous carbon (82.2 $\%$ ) but with slight shift to mesoporosity $(17.8 \%)$.

\section{Adsorption of Methylene Blue:-}

Fig. (9 (a)) shows the adsorption isotherms of MB on the CX samples synthesized at different R-F pH values and fixed $\mathrm{CT}$ of $750^{\circ} \mathrm{C}$ in nitrogen atmosphere. The graphs are plotted in the form of the amount of MB adsorbed (X) per unit mass of carbon, against the concentration of MB remaining in solution, Ceq. The adsorption isotherms show type-H according to the Giles classification (Giles et al., 1960). They show very steep behavior with various degrees of sharpness or roundness at the low concentration values, tending to a plateau parallel to the Ceq-axis. Type-H indicates high affinity isotherm with strong preferential adsorption of the solute (Giles et al., 1960). The results of the Langmuir and Freundlich plots show satisfactory straight lines, which indicate that both of these 
adsorption models are applicable. The Langmuir plots are represented in Fig. (10 (a)), whereas the Freundlich plots are illustrated in Fig. (11 (a)).

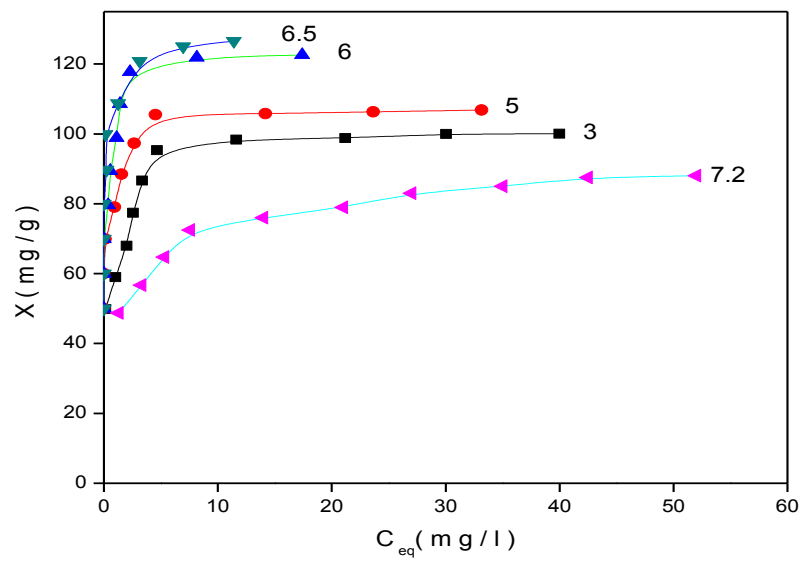

(a)

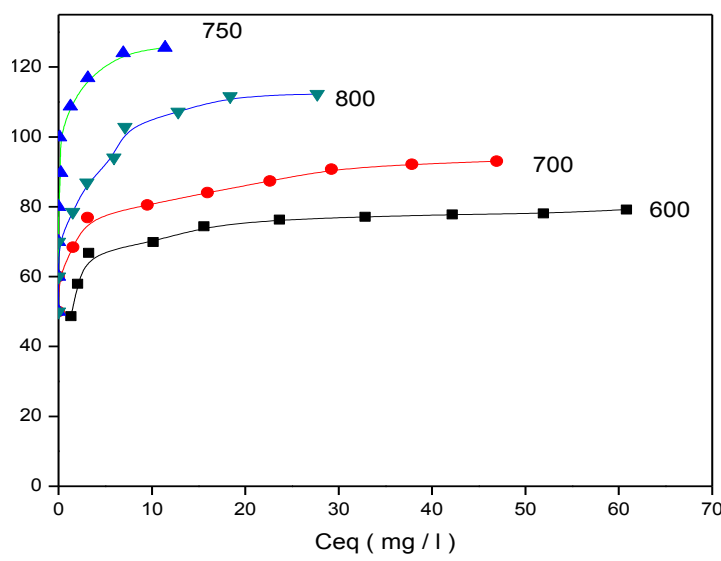

(b)

Fig. 9:- The adsorption isotherms of MB on the CXs obtained under different conditions: (a) different R-F solutions $\mathrm{pH}$ values and (b) different CTs.

Table (4) summarizes the adsorption parameters $\left(\mathrm{X}_{\mathrm{m}}, \mathrm{K}_{\mathrm{L}}, \mathrm{n}_{\mathrm{F}}\right.$ and $\left.\mathrm{K}_{\mathrm{F}}\right)$ derived from both adsorption models. The following can be observed: i) Application of the Langmuir equation is more satisfactory as evident from their higher correlation coefficients $\left(\mathrm{R}^{2}\right)$ compared to those of the Freundlich equation. ii) The dye adsorption capacity increases with the increase of the $\mathrm{R}-\mathrm{F}$ solution $\mathrm{pH}$ value up to $\mathrm{pH}=6.5$ then declines. The adsorption capacity increases continuously from 102 to $128 \mathrm{mg}$. $\mathrm{g}^{-1}$ with increasing the initial $\mathrm{pH}$ value from 3.0 to 6.5 , respectively. This can be ascribed to the increased adsorption space on the CX surface, due to the increase in the surface area and number of pores accessible to $\mathrm{MB}$ molecules with raising the $\mathrm{R}-\mathrm{F}$ solution $\mathrm{pH}$ value up to $\mathrm{pH}=6.5$. The sample prepared at $\mathrm{pH}=7.2$ has a lower surface area, lower pore volume, and, as a result, lower uptake of MB.

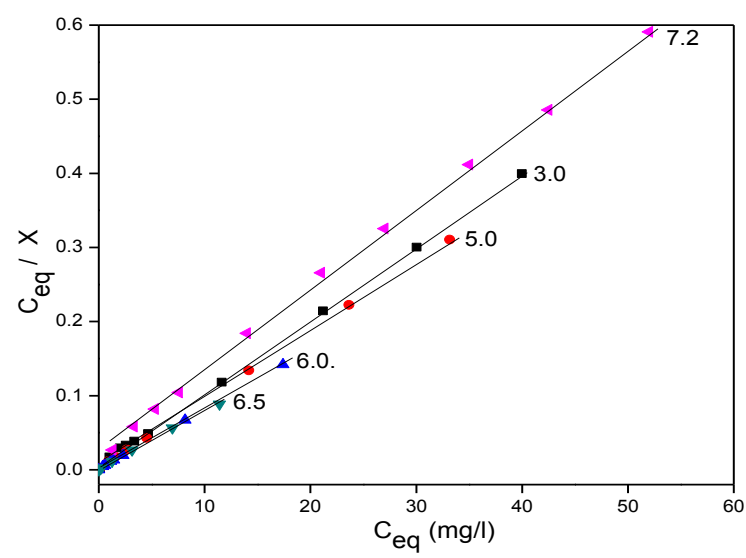

(a)

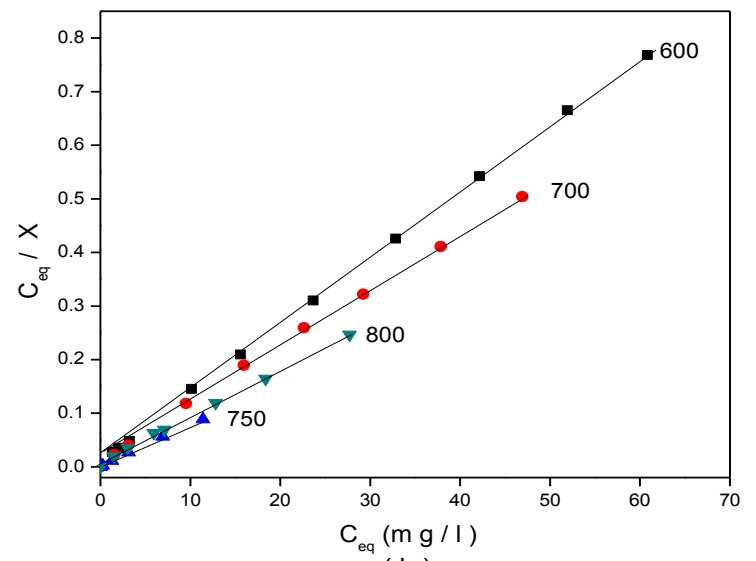

(b)

Fig. 10:- Langmuir plots of MB by the CXs obtained under different conditions: (a) different R-F solutions pH values, and (b) different CTs. 


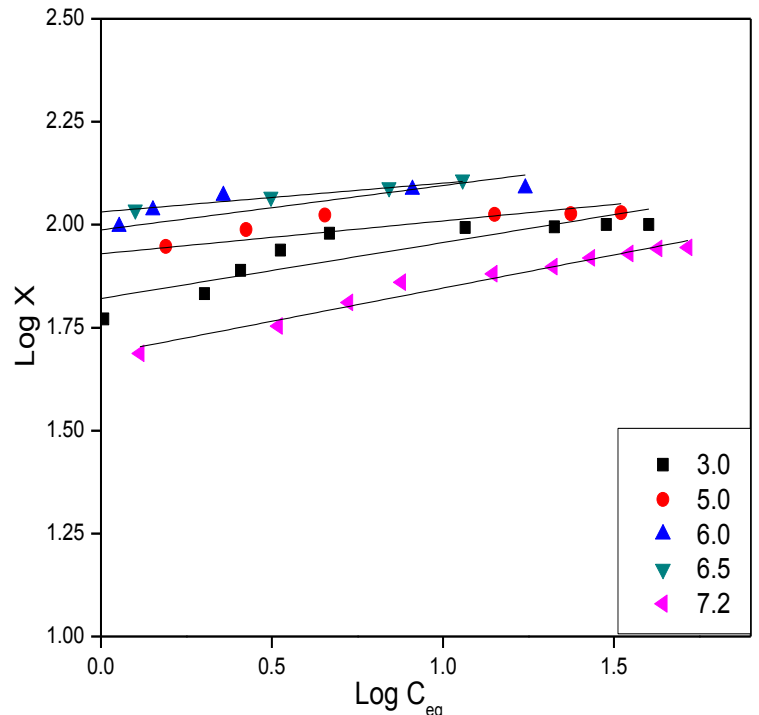

(a)

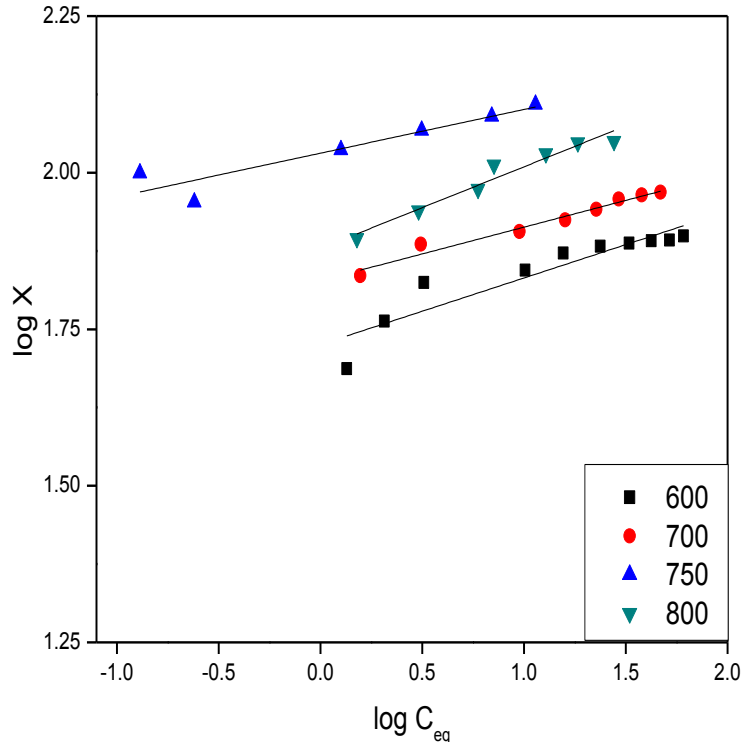

(b)

Fig. 11:- Freundlich plots of MB by the CXs obtained under different conditions: (a) different R-F solutions pH values, and (b)different CTs.

Table 4:- Equilibrium values of MB adsorption, surface area accessible to M.B and ratio to nitrogen surface area for the investigated CXs.

\begin{tabular}{|c|c|c|c|c|c|c|c|c|c|}
\hline \multirow{2}{*}{$\begin{array}{l}\text { Sample } \\
\text { notation }\end{array}$} & \multicolumn{3}{|c|}{ Langmuir-plots } & \multicolumn{3}{|c|}{ Freundlich-plots } & \multirow{2}{*}{$\underset{\left(\mathbf{m}^{2} \cdot \mathrm{g}^{-1}\right)}{\mathrm{S}_{\mathrm{MB}}}$} & \multirow{2}{*}{$S_{N_{2}}^{\alpha}$} & \multirow{2}{*}{$\begin{array}{c}\mathbf{S}_{\mathbf{M B}} / \\
S_{N_{2}}^{\alpha}\end{array}$} \\
\hline & $\begin{array}{c}\mathrm{X}_{\mathrm{m}} \\
\left(\mathrm{mg} \cdot \mathrm{g}^{-1}\right)\end{array}$ & $\begin{array}{c}\mathrm{K}_{\mathrm{L}} \\
\left(1 . \mathrm{mg}^{-1}\right)\end{array}$ & $\mathrm{R}^{2}$ & $\begin{array}{c}\mathrm{K}_{\mathrm{F}} \\
\left(\mathrm{mg} \cdot \mathrm{g}^{-1}\right)\end{array}$ & $\mathrm{n}_{\mathrm{F}}$ & $\mathrm{R}^{2}$ & & & \\
\hline \multicolumn{10}{|c|}{ Effect of $\mathrm{pH}$} \\
\hline CX3.0(MW)750 & 102 & 1.751 & 0.9996 & 70.790 & 7.407 & 0.8619 & 397 & 566 & 0.702 \\
\hline CX5.0(MW)750 & 108 & 6.643 & 0.9999 & 84.950 & 12.515 & 0.8660 & 421 & 590 & 0.713 \\
\hline CX6.0(MW)750 & 123 & 8.345 & 0.9996 & 97.140 & 9.286 & 0.7830 & 483 & 604 & 0.799 \\
\hline CX6.5(MW)750 & 128 & 12.59 & 0.9987 & 107.424 & 14.308 & 0.8445 & 499 & 701 & 0.713 \\
\hline CX7.2(MW)750 & 91 & 0.473 & 0.9987 & 48.421 & 6.210 & 0.9641 & 205 & 511 & 0.401 \\
\hline \multicolumn{10}{|c|}{ Effect of CT } \\
\hline CX6.5(MW)600 & 80 & 1.0024 & 0.9998 & 53.156 & 9.406 & 0.8441 & 313 & 311 & 1.007 \\
\hline CX6.5(MW)700 & 93 & 1.3827 & 0.9983 & 67.234 & 11.713 & 0.9649 & 365 & 489 & 0.906 \\
\hline CX6.5(MW)750 & 128 & 12.59 & 0.9987 & 107.424 & 14.308 & 0.8445 & 499 & 701 & 0.713 \\
\hline CX7.2(MW)800 & 113 & 2.135 & 0.9976 & 75.664 & 7.666 & 0.9462 & 443 & 614 & 0.721 \\
\hline
\end{tabular}

The adsorption capacity of CXs depends not only on their textural characteristics, but also on their surface chemistry, i.e. the nature of the CX surface, c.f. Table (5) and Fig. (12 (a, b)). The pH of the dye solutions was not adjusted, so that the $\mathrm{pH}$ of the $\mathrm{CX}$ surface becomes an important determining factor. The $\mathrm{pH}$ determines the surface charge of the carbon material, and therefore the electrostatic interaction (attractive or repulsive) between the dye molecules and the adsorbent (Moreno-Castilla and Rivera-Utrilla, 2001). The maximum adsorptivity belongs to the CX6.5 sample. At lower $\mathrm{pH}$ values, excessive protonation of the carbon surface occurs which enhances the electrostatic repulsion between the $\mathrm{CX}$ surface and MB cations (positively charged), resulting in lower adsorption capacity. At a higher $\mathrm{pH}$ value, although the surface of the adsorbent is negatively charged which could favor the adsorption of positively charged $\mathrm{MB}$, the low porosity and surface area decrease this effect. In this case the net synergistic effect of texture properties and surface chemistry of CX7.2 is to reduce the adsorptivity towards MB. 


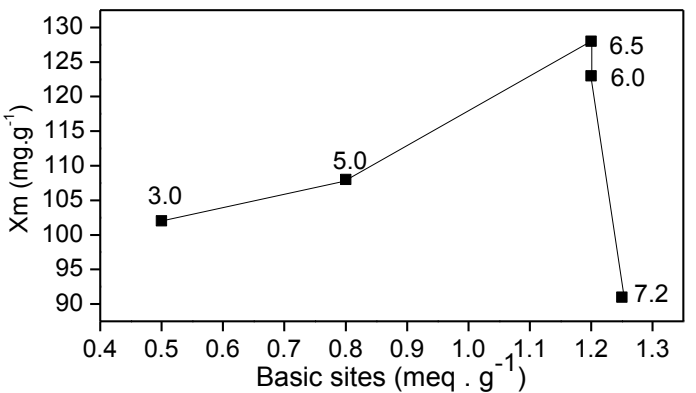

(a)

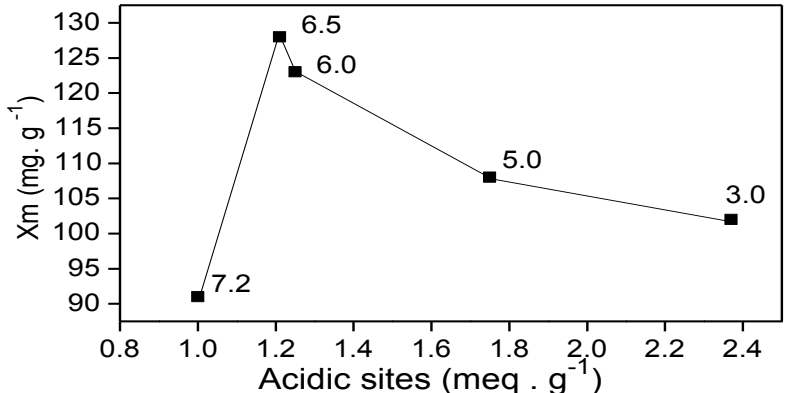

(b)

Fig. 12:- Adsorption amounts $X_{m}$ of MB vs. surface basic (a) and acidic (b) sites obtained from Boehm titration for the CXs obtained at different $\mathrm{R}-\mathrm{F}$ solutions $\mathrm{pH}$ values.

Table 5:- Adsorption amounts $X_{m}\left(\mu \mathrm{mol} / \mathrm{m}^{2}\right)$ of MB, total acidic and basic sites (meq $/ \mathrm{m}^{2}$ ) obtained from Boehm titration for the investigated carbons

\begin{tabular}{|c|c|c|c|}
\hline $\begin{array}{c}\text { Sample } \\
\text { notation }\end{array}$ & $\begin{array}{c}\mathrm{X}_{\mathrm{m}} \\
\left(\mathrm{mg} \cdot \mathrm{g}^{-1}\right)\end{array}$ & $\begin{array}{c}\text { Total acidic sites } \\
\left(\mathrm{meq} \cdot \mathrm{g}^{-1}\right)\end{array}$ & $\begin{array}{c}\text { Basic sites } \\
\left(\mathrm{meq}_{\mathrm{g}} \mathrm{g}^{-1}\right)\end{array}$ \\
\hline \multicolumn{7}{|c|}{ Effect of $\mathrm{pH}$} \\
\hline CX3.0(MW)750 & 102 & 2.37 & 0.5 \\
\hline CX5.0(MW)750 & 108 & 1.75 & 0.8 \\
\hline CX6.0(MW)750 & 123 & 1.25 & 1.20 \\
\hline CX6.5(MW)750 & 128 & 1.21 & 1.20 \\
\hline CX7.2(MW)750 & 91 & 1.00 & 0.60 \\
\hline \multicolumn{7}{|c|}{ Effect of CT } \\
\hline CX6.5(MW)600 & 80 & 1.30 & 1.00 \\
\hline CX6.5(MW)700 & 93 & 1.27 & 1.20 \\
\hline CX6.5(MW)750 & 128 & 1.21 & 1.22 \\
\hline
\end{tabular}

Taking the evaluated $X_{m}$ and the value of cross-sectional area covered by an adsorbed MB molecule as $120 \AA^{2}$ (Giles, 1969), the surface areas accessible to $\mathrm{MB}\left(\mathrm{S}_{\mathrm{MB}}\right)$ were determined. The estimated $\mathrm{S}_{\mathrm{MB}}$ values are given in

Table (4) along with the $\left(\mathrm{S}_{\mathrm{MB}} / S_{t}^{\alpha}\right)$ ratios. A comparative representation of the data for total surface area $\left(S_{t}^{\alpha}\right)$ obtained from $\mathrm{N}_{2}$ sorption isotherms and surface area accessible to methylene blue $\left(\mathrm{S}_{\mathrm{MB}}\right)$ for the CX samples are given in Fig. $\left(13\right.$ (a)). The CX6.5 sample has higher $S_{M B}$ value $\left(S_{M B}=499 \mathrm{~m}^{2} \cdot \mathrm{g}^{-1}\right)$ compared to that for the CX6.0 sample $\left(\mathrm{S}_{\mathrm{MB}}=483 \mathrm{~m}^{2} \cdot \mathrm{g}^{-1}\right)$, which can be correlated to the less surface acidic nature of this sample (acidic sites $=$ $1.21 \times 10^{-3}\left(\right.$ meq. $\left.\mathrm{g}^{-1}\right)$ ) compared to that of the CX6.0 sample (acidic sites $=1.25 \times 10^{-3}$ (meq.g $\left.{ }^{-1}\right)$ ) [c.f. Table (5)]. However the $\mathrm{S}_{\mathrm{MB}} / S_{N_{2}}^{\alpha}$ value for the CX6.5 sample is lower than that for the CX6.0 sample (i.e. 00.713 and 0.799 , respectively) which can be attributed to the development of micro pores inaccessible to MB in the CX6.5 sample. The ability of these CXs for adsorption of MB is reduced by surface acidic groups and enhanced by surface basic sites.

Fig.( 9 (b)) shows the adsorption isotherms of MB on the CXs prepared at different CTs in $\mathrm{N}_{2}$ atmosphere and fixed $\mathrm{R}-\mathrm{F} \mathrm{pH}$ value of 6.5. The isotherms show also type-H according to the Giles classification (Giles et al., 1960). The results of the Langmuir and Freundlich plots show satisfactory straight lines. The Langmuir plots are represented in Fig. (10 (b)), whereas the Freundlich plots are illustrated in Fig.(11 (b)). The Langmuir parameters $\left(\mathrm{X}_{\mathrm{m}}\right.$ and $\left.\mathrm{K}_{\mathrm{L}}\right)$ and Freundlich constants $\left(\mathrm{K}_{\mathrm{F}}\right.$ and $\left.\mathrm{n}_{\mathrm{F}}\right)$ are given also in Table (4). It can be observed that the dye adsorption capacity increases continuously with the increase of the carbonization temperature up to $750^{\circ} \mathrm{C}$ then declines, the highest value is observed for the CX750 sample. A comparative representation of the data for the CXs obtained at different CTs are given in Table (4) along with the $\left(\mathrm{S}_{\mathrm{MB}} / s_{t}^{\alpha}\right)$ ratios, and are represented graphically in Fig. (13 (b)). Table (4)

reflects a gradual decrease in the $\mathrm{MB}$ accessible surface area ratio (i.e. $\mathrm{S}_{\mathrm{MB}} / s_{t}^{\alpha}$ ) with the increase of the $\mathrm{CT}$ up to 
$750^{\circ} \mathrm{C}$. The effect of raising the $\mathrm{CT}$ was found to increase the porosity up to $750{ }^{\circ} \mathrm{C}$, as indicated previously from the calculated values of $s_{t}^{\alpha}, s_{n}^{\alpha}$, and $s_{\text {mic }}^{\alpha}$, c.f. Fig.(8 (b)). Also, the non-microporous surface area is $82.3 \%$ of the total surface area for the CX600 sample. It decreases sharply to $1.8 \%$ by raising the CT up to $800{ }^{\circ} \mathrm{C}$ (i.e. the CX800 sample), [c.f. Table (3)]. It should be remembered here that MB, due to its bulky size, measures only the surface area within pores of diameter $\geq 15 \AA$ (Girgis and El-Hendawy, 2002).

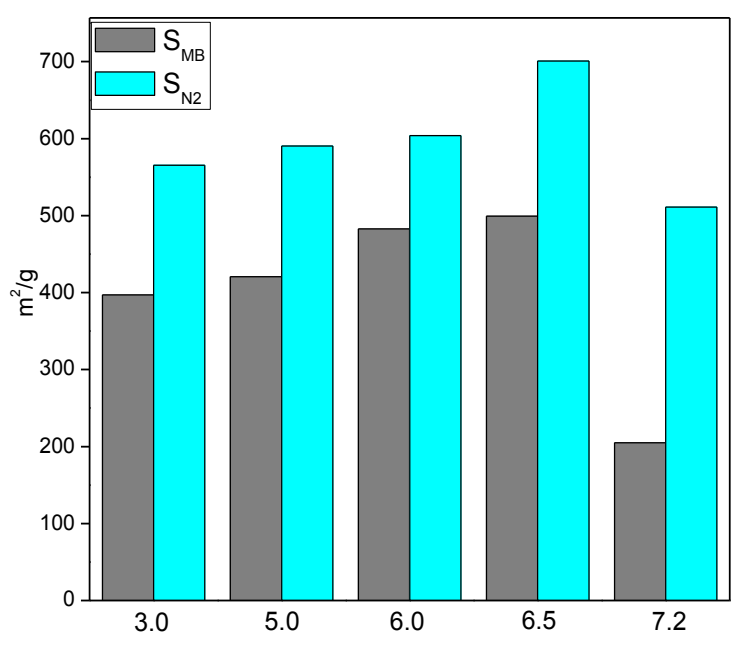

(a)

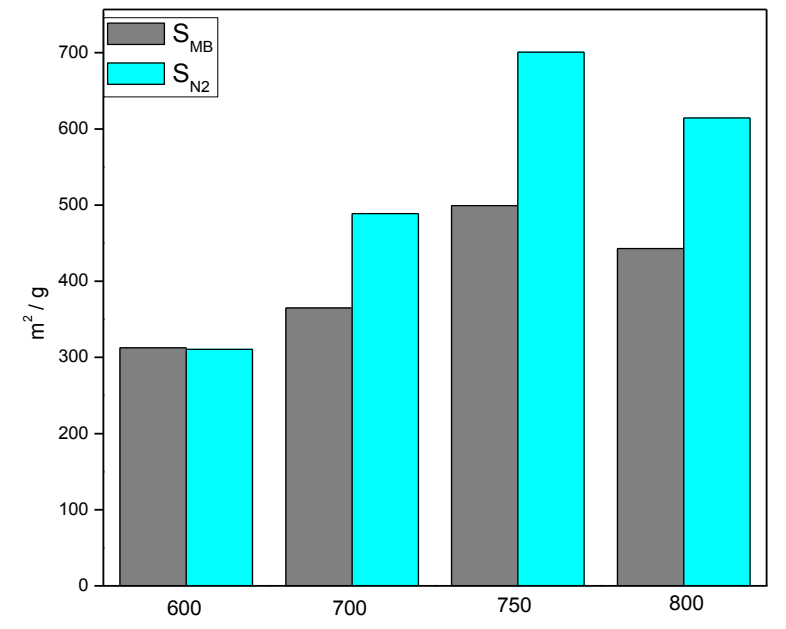

(b)

Fig. 13:- A comparative representation of the data for total surface area $\left(S_{t}^{\alpha}\right)$ obtained from $N_{2}$ sorption isotherms and surface area accessible to methylene blue $\left(\mathrm{S}_{\mathrm{MB}}\right)$ for the CXs obtained under different conditions: (a) different $\mathrm{R}-\mathrm{F}$ solutions $\mathrm{pH}$ values, and (b) different CTs.

The results obtained from Fig. (14) are in agreement with those observed in Fig. (12), i.e. the ability of these CXs for adsorption of $\mathrm{MB}$ is reduced by surface acidic groups and enhanced by surface basic ones.

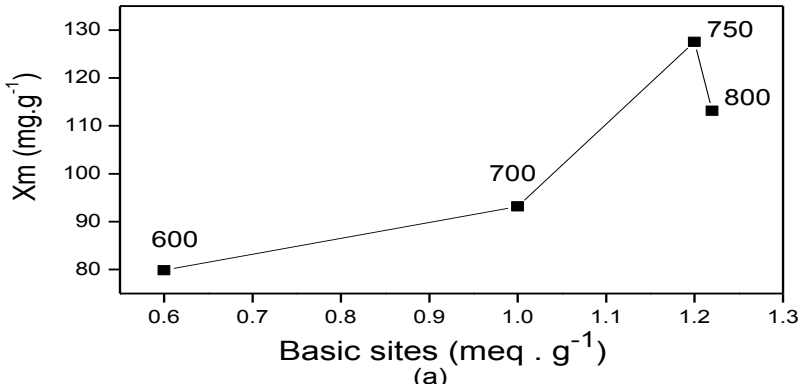

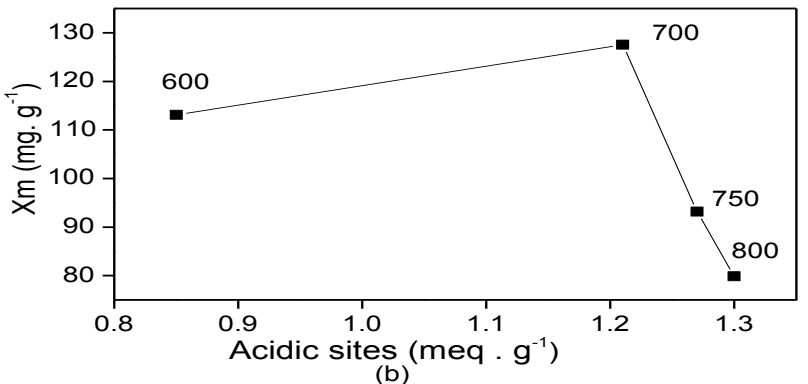

(b)

Fig. 14:- Adsorption amounts $X_{m}$ of $M B$ vs. surface basic (a) and acidic (b) sites obtained from Boehm titration for

\section{Conclusions:-} the CXs obtained at different CTs.

1. The MW induced synthesis method of CXs confirmed the following: a) By varying synthesis conditions such as initial solution $\mathrm{pH}$ and calcinations temperature, it is possible to obtain nanostructured porous carbons with different physicochemical properties. The chemical nature of the CXs surfaces depends strongly on the synthesis conditions. b) The texture characteristics obtained from the BET-equation and $\alpha_{\mathrm{s}}$ - plots indicate developed carbon microporosity with some mesoporosity, which depends on the preparation conditions. c) The removal capacity of MB is governed by the chemical structure of the CX surface (i.e. the acidic and basic nature) as well as the diffusion through the intricate internal porosity. d) The best conditions for producing CXs by the MW induced synthesis method is at initial solution $\mathrm{pH}$ value of 6.5 and $\mathrm{CT}$ of $750^{\circ} \mathrm{C}$. These conditions 
favor higher yield and carbon content, more surface function groups, higher surface area, wider pore volume and more developed mesoporosity.

2. The effect of the synthesis method confirmed that the MW assisted method has a lot of advantages over the conventional method. The main advantage is the saving of time, resulting in a reduction in the energy consumed, also the prepared CXs have higher surface area, more developed porosity, higher carbon content and more yield than those obtained by the conventional synthesis method.

\section{References:-}

1. Alegre, C., Gálvez, M., Sebastián, D., Moliner, R., Lázaro, M., 2012. Influence of synthesis pH on textural properties of carbon xerogels as supports for Pt/CXs catalysts for direct methanol fuel cells. international journal of electrochemistry 2012.

2. Al-Muhtaseb, S.A., Ritter, J.A., 2003. Preparation and properties of resorcinol-formaldehyde organic and carbon gels. Advanced Materials 15, 101-114.

3. Álvarez, S., Ribeiro, R., Gomes, H., Sotelo, J., García, J., 2015. Synthesis of carbon xerogels and their application in adsorption studies of caffeine and diclofenac as emerging contaminants. Chemical Engineering Research and Design 95, 229-238.

4. Bansal, R.C., Goyal, M., 2005. Activated carbon adsorption. CRC press.

5. Boehm, H., 2002. Surface oxides on carbon and their analysis: a critical assessment. Carbon 40, 145-149.

6. Brunauer, S., Deming, L.S., Deming, W.E., Teller, E., 1940. On a theory of the van der Waals adsorption of gases. Journal of the American Chemical society 62, 1723-1732.

7. Brunauer, S., Emmett, P.H., Teller, E., 1938. Adsorption of gases in multimolecular layers. Journal of the American Chemical society. 60, 309-319.

8. Caddick, S., 1995. Microwave assisted organic reactions. Tetrahedron 51, 10403-10432.

9. Calvo, E.G., Arenillas, A., Menéndez, J.Á., 2011. Designing nanostructured carbon xerogels. INTECH Open Access Publisher.

10. Carrott, P., Roberts, R., Sing, K., 1987. Adsorption of nitrogen by porous and non-porous carbons. Carbon 25, 59- 68.

11. Figueiredo, J., Pereira, M., Freitas, M., Orfao, J., 1999. Modification of the surface chemistry of activated carbons. carbon 37, 1379-1389.

12. Gedye, R.N., 2002. Organic Synthesis using Microwaves in Homogeneous Media. Microwaves in organic synthesis, 115-146.

13. Giles, C., MacEwan, T., Nakhwa, S., Smith, D., 1960. 786. Studies in adsorption. Part XI. A system of classification of solution adsorption isotherms, and its use in diagnosis of adsorption mechanisms and in measurement of specific surface areas of solids. Journal of the Chemical Society. (Resumed), 3973-3993.

14. Giles, C.H., 1969. Determination of specific surface areas of powders by dyes. Journal of the American Chemical Society. 91, 759-759.

15. Girgis, B.S., El-Hendawy, A.-N.A., 2002. Porosity development in activated carbons obtained from date pits under chemical activation with phosphoric acid. Microporous and mesoporous materials 52, 105-117.

16. Girgis, M. M., 1993. Effect of copper (II) content and metal vanadate formation on the structure, grain morphology and electrical conductance behaviour of $\mathrm{Mg}_{1.0-\mathrm{x}}-\mathrm{Cu}_{\mathrm{x}}-\mathrm{V}_{2 \cdot 0}(0.0 \leq \mathrm{X} \leq 1.0)$ mixed oxide systems. Journal of materials science 28, 4925-4933.

17. Job, N., Pirard, R., Marien, J., Pirard, J.-P., 2004. Porous carbon xerogels with texture tailored by pH control during sol-gel process. Carbon 42, 619-628.

18. Job, N., Théry, A., Pirard, R., Marien, J., Kocon, L., Rouzaud, J.-N., Béguin, F., Pirard, J.-P., 2005. Carbon aerogels, cryogels and xerogels: influence of the drying method on the textural properties of porous carbon materials. Carbon 43, 2481-2494.

19. Kakunuri, M., Vennamalla, S., Sharma, C.S., 2015. Synthesis of carbon xerogel nanoparticles by inverse emulsion polymerization of resorcinol-formaldehyde and their use as anode materials for lithium-ion battery. RSC Advances 5, 4747-4753.

20. Kang, K.Y., Hong, S.J., Lee, B.I., Lee, J.S., 2008. Enhanced electrochemical capacitance of nitrogen-doped carbon gels synthesized by microwave-assisted polymerization of resorcinol and formaldehyde. Electrochemistry Communications 10, 1105-1108.

21. Khetre, S.M., Jadhav, H., Bangale, S., Jagdale, P., Bamane, S.R., 2011. Use of mixed metal oxide as a catalyst in the decomposition of hydrogen peroxide. Advances in Applied Science Research 2, 1.

22. Le Van, Q., Gourdenne, A., 1987. Microwave curing of epoxy resins with diaminodiphenylmethane-I. General features. European polymer journal 23, 777-780. 
23. Li, D., Zang, J., Zhang, J., Ao, K., Wang, Q., Dong, Q., Wei, Q, 2016. Sol-Gel Synthesis of Carbon XerogelZnO Composite for Detection of Catechol. Materials 9, 282-292.

24. Li, S.-M., Sun, S.-L., Ma, M.-G., Dong, Y.-Y., Fu, L.-H., Sun, R.-C., Xu, F., 2013. Lignin-based carbon/CePO4 nanocomposites: Solvothermal fabrication, characterization, thermal stability, and luminescence. BioResources 8, 4155-4170.

25. Lufrano, F., Staiti, P., Calvo, E., Juárez-Pérez, E., Menéndez, J., Arenillas, A., 2011. Carbon xerogel and manganese oxide capacitive materials for advanced supercapacitors. Int. J. Electrochem. Sci 6, 596-612.

26. Moreno-Castilla, C., Maldonado-Hódar, F., 2005. Carbon aerogels for catalysis applications: An overview. Carbon 43, 455-465.

27. Moreno-Castilla, C., Rivera-Utrilla, J., 2001. Carbon materials as adsorbents for the removal of pollutants from the aqueous phase. MRS Bulletin 26, 890-894.

28. Naseri, I., Kazemi, A., Bahramian, A.R., Razzaghi Kashani, M., 2014. Preparation of organic and carbon xerogels using high-temperature-pressure sol-gel polymerization. Materials \& Design 61, 35- 40.

29. O'reilly, J., Mosher, R., 1983. Functional groups in carbon black by FTIR spectroscopy. Carbon 21, 47-51.

30. Ordeñana-Martínez, A., Rincón, M., 2016. Composite MWCNT/carbon xerogel-nafion electrode for energy storage. Journal of Solid State Electrochemistry 20, 1391-1396.

31. Oyedoh, E.A., Albadarin, A., Walker, G., Mirzaeian, M., Ahmad, M., 2013. Preparation of controlled porosity resorcinol formaldehyde xerogels for adsorption applications. Chemical Engineering Transactions 32, 16511656.

32. Pradhan, B.K., Sandle, N., 1999. Effect of different oxidizing agent treatments on the surface properties of activated carbons. Carbon 37, 1323-1332.

33. Sellés-Pérez, M.J., Martín-Martínez, J.M., 1991. Application of $\alpha$ and $n$ plots to $\mathrm{N}_{2}$ adsorption isotherms of activated carbons. Journal of the Chemical Society, Faraday Transactions 87, 1237-1243.

34. Shafeeyan, M.S., Daud, W.M.A.W., Houshmand, A., Shamiri, A., 2010. A review on surface modification of activated carbon for carbon dioxide adsorption. Journal of Analytical and Applied Pyrolysis 89, 143-151.

35. Yoon, S.B., Chai, G.S., Kang, S.K., Yu, J.-S., Gierszal, K.P., Jaroniec, M., 2005. Graphitized pitch-based carbons with ordered nanopores synthesized by using colloidal crystals as templates. Journal of the American Chemical Society 127, 4188-4189.

36. Zanto, E.J., Al-Muhtaseb, S.A., Ritter, J.A., 2002a. Sol-gel-derived carbon aerogels and xerogels: Design of experiments approach to materials synthesis. Industrial \& engineering chemistry research 41, 3151-3162.

37. Zanto, E.J., Al-Muhtaseb, S.A., Ritter, J.A., 2002b. Sol- Gel-Derived Carbon Aerogels and Xerogels: Design of Experiments Approach to Materials Synthesis. Industrial \& engineering chemistry research 41, 3151-3162.

38. Zapata-Benabithe, Z., Diossa, G., Castro, C.D., Quintana, G., 2016. Activated Carbon Bio-Xerogels as Electrodes for Super Capacitors Applications.4th International Conference on Process Engineering and Advanced Materials. Procedia Engineering 148,18 - 24.

39. Zubizarreta, L., Arenillas, A., Domínguez, A., Menéndez, J., Pis, J., 2008. Development of microporous carbon xerogels by controlling synthesis conditions. Journal of Non-Crystalline Solids 354, 817-825. 